Research Article

\title{
Experiment on Natural Frequency Change of Reinforced Concrete Members under Low Cycle Loading
}

\author{
Zhenhao Zhang $\mathbb{D}^{1},{ }^{1}$ Feng Cao $\mathbb{D}^{1},{ }^{1}$ Jianyu Yang $\mathbb{D}{ }^{2}$, and Zhigang He $\mathbb{D}^{1}$ \\ ${ }^{1}$ School of Civil Engineering, Changsha University of Science and Technology, $9602^{\text {nd }}$ Section of Wanjiali South Road, Changsha, \\ Hunan 410114, China \\ ${ }^{2}$ School of Civil Engineering, Hunan University, 2 Lushan South Road, Changsha, Hunan 410082, China
}

Correspondence should be addressed to Zhenhao Zhang; zhangzhenhao@csust.edu.cn

Received 14 March 2018; Revised 19 July 2018; Accepted 7 August 2018; Published 10 October 2018

Academic Editor: Filippo Ubertini

Copyright (C) 2018 Zhenhao Zhang et al. This is an open access article distributed under the Creative Commons Attribution License, which permits unrestricted use, distribution, and reproduction in any medium, provided the original work is properly cited.

\begin{abstract}
The natural frequency change of reinforced concrete (RC) members during damage when subjected to low cycle loading was studied through horizontal cyclic loading experiments. Three groups of RC flexural members were subjected to horizontal, harmonic, low cycle loading to simulate earthquake conditions. The relation of instantaneous load, instantaneous displacement, and instantaneous natural frequency during loading was deduced. Using the resulting equation, the test members' natural frequencies at any moment during loading could be calculated accurately. Then the natural frequency change curves and their fitting equations were also obtained. The impact of loading period $T$ and loading amplitude $A$ on a test member's damage rate $V$ was analyzed, which showed that the impact of $T$ on $V$ was quadratic, and the relation between $A$ and $V$ was linear. Finally, by fitting experimental data of number of loading cycles $N$, loading amplitude $A$, loading period $T$, and natural frequency $\omega$, a three-variable function, $\omega(N, A, T)$, was determined, revealing the change process of test members' frequencies under arbitrary harmonic vibrations.
\end{abstract}

\section{Introduction}

It is important for engineers to assess the integrity or damage status of a structure after severe cyclic loading, such as from an earthquake. One method for diagnosing the status of structural damage relies on the structural natural frequency [1-8], as the damage of structural members will lead to changes in this parameter. Therefore, determining the variation in structural natural frequency can help identify structural damage.

Most recent research focuses on identifying structural damage through the natural frequency change. However, there are few such investigations. Abraham et al. [9] tested the change in natural frequency when beam prestress changed and found that natural frequency increases as prestress decreases. One experimental study [10] discussed the effectiveness of frequency and time domain identification algorithms in monitoring the structural health of frame structures. The frequency change and stiffness degradation law of an infill wall at different stages was studied when the main structure was damaged [11]. Another study [12] focused on differentiating between the effects of changes in the natural frequency of a suspension bridge due to environmental variations and those resulting from structural damage. A study [13] showed how to use the method of natural frequency determination of a cracked reinforced concrete beam to assess its damage. A study of the natural frequency change of reinforced concrete structures under ordinary drying conditions [14] pointed out possible mechanisms of natural frequency change. A natural frequency change correlation approach [15] was used to detect the damage of a cantilever beam. Two studies $[16,17]$ found that higher-order frequencies are more sensitive than lowerorder frequencies to internal microstructure damage. An analysis of long-term monitoring data [18] found that the frequency of a cable-stayed bridge declined with increases in temperature. To summarize, studies of natural frequency changes during structural damage are insufficient, and most research on this topic is qualitative rather than quantitative. There is scant work on the characteristics of natural frequency change during the damage process under a low cycle fatigue load. Through a pseudostatic experiment $[19,20]$, this article systematically studied the natural frequency change of a reinforced concrete (RC) member during the damage 
process under low cycle loading and established a quantitative functional relationship of natural frequency change. This study also provided some theoretical basis for quantitative research of the damage process of an RC structure due to an earthquake.

\section{Experiment and Specimen Design}

An RC flexural member was used as the research object in a low cycle loading experiment to determine the change characteristics of an RC structural member during seismic damage. By changing the section size and reinforcement, three groups of nine test members were designed with different sizes, strengths, and stiffnesses. The structures of the test members are shown in Figures 1-3, and their basic parameters are listed in Table 1. Each flexural member was consolidated with a ground beam that was anchored to the floor, providing consolidated support to the bottom.

The following materials were used. Concrete used in the test members was C30 (GB50010-2010, Ministry of Housing and Urban-Rural Development of the People's Republic of China (MOHURD)) [21]. The longitudinal reinforcements of the first group of test members were HRB335 and those of the second and the third group were HRB400 (both GB50010-2010). The stirrups of the first and third group were HRB235 and those of the second group were HPB300.

\section{Loading Plan}

3.1. Loading System. The loading system consisted of a hydraulic servo actuator, reaction wall, connecting pieces, and jack and auxiliary equipment, as shown in Figure 4. Installed on the reaction wall parallel to the ground, the hydraulic servo actuator applied a horizontal load to the top of the test member. Test members were subjected to horizontal reciprocating loading by an MTS electrohydraulic servo loading system to simulate earthquake action [22]. The displacement-control mode was adopted as the load method [23]. The ground beam was anchored to the floor by bolt and jack to eliminate horizontal movement or rotation during the test. Horizontal reciprocating loading was applied to each test member until it was destroyed.

The common method of acquiring a test member's frequency during structural damage is to stop loading and use special instruments to measure the test member's frequency at regular time intervals $[24,25]$. That method is complex because the connection between the test member and actuator must be repeatedly disassembled and assembled. In addition, it is difficult to measure the test member's frequency with high precision $[13,26]$. Therefore, in this study, the force and displacement during the loading process were measured in real time by a sensor installed inside the actuator.

3.2. Specimens' Yield Loads and Yield Displacements. A reinforced concrete seismic member's yield moment can be approximated as [27]

$$
M_{\mathrm{y}}=0.9 f_{\mathrm{y}} A_{\mathrm{s}} h_{0},
$$

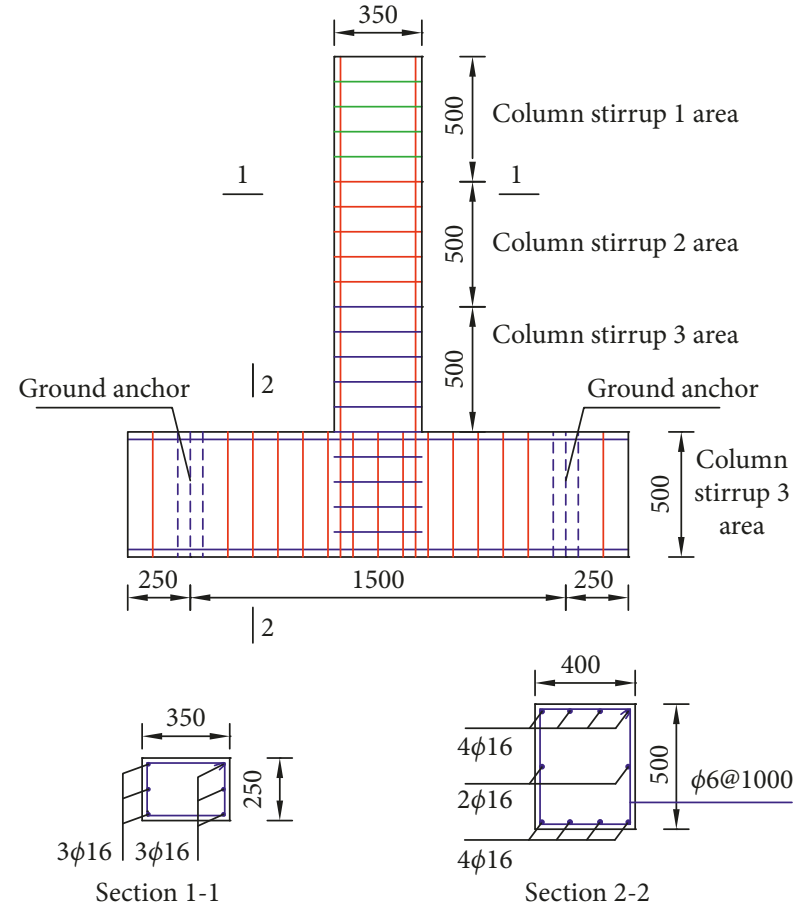

FIGURE 1: Size and reinforcement of the first group of test members.

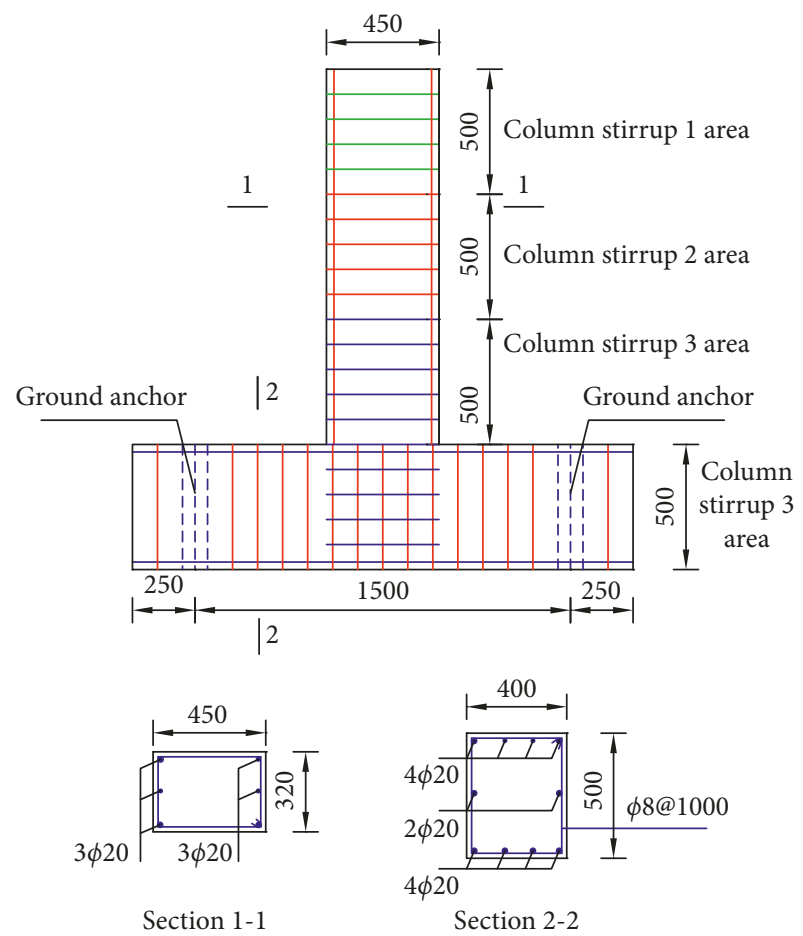

FIgURE 2: Size and reinforcement of the second group of test members.

where $f_{\mathrm{y}}$ is the steel yield strength, $A_{\mathrm{s}}$ is the reinforced area, and $h_{0}$ is the effective depth of section of the test member.

The yield load is

$$
F_{\mathrm{y}}=\frac{M_{\mathrm{y}}}{H},
$$




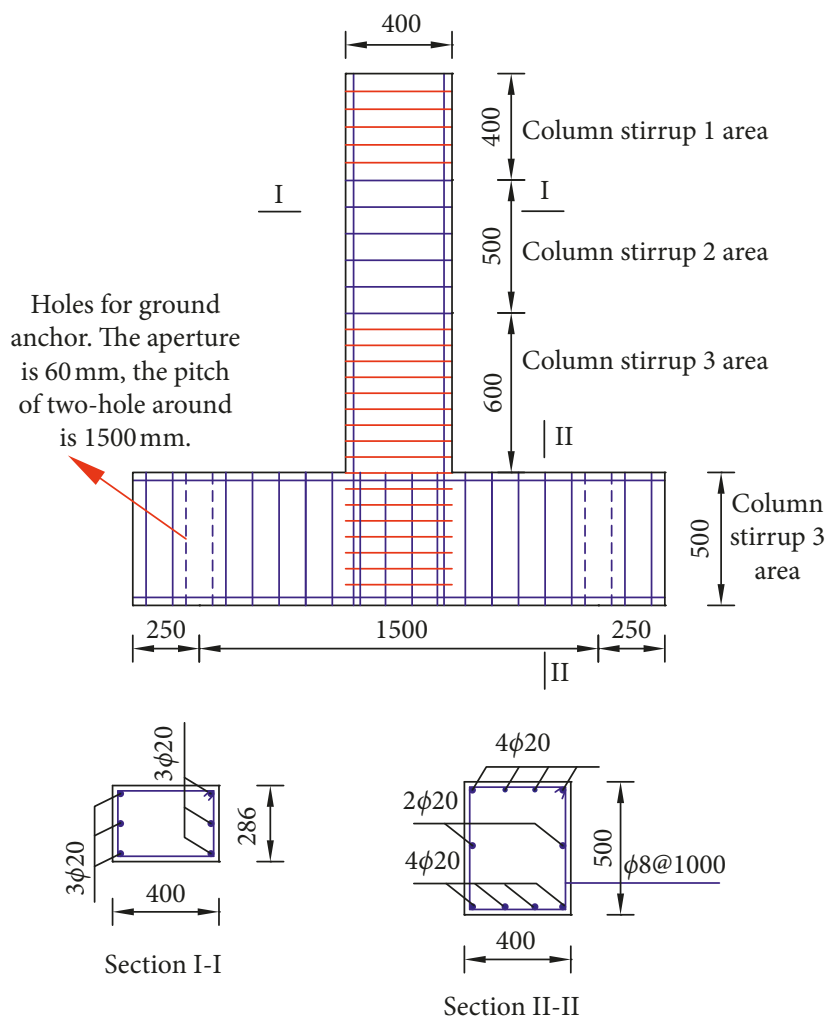

FIGURE 3: Size and reinforcement of the third group of test members.

TABLE 1: Basic parameters of test members.

\begin{tabular}{|c|c|c|c|c|c|c|c|}
\hline $\begin{array}{l}\text { Group } \\
\text { (specimen number) }\end{array}$ & $\begin{array}{c}\text { Section } \\
\text { size }(\mathrm{mm}) \\
\end{array}$ & $\begin{array}{l}\text { Reinforcement } \\
\text { ratio }(\%) \\
\end{array}$ & $\begin{array}{c}\text { Section size of } \\
\text { ground beam }(\mathrm{mm})\end{array}$ & $\begin{array}{c}\text { Area } 1 \text { of } \\
\text { stirrups }\end{array}$ & $\begin{array}{l}\text { Area } 2 \text { of } \\
\text { stirrups }\end{array}$ & $\begin{array}{c}\text { Area } 3 \text { of } \\
\text { stirrups }\end{array}$ & $\begin{array}{c}\text { Amount of } \\
\text { specimens }\end{array}$ \\
\hline 1st group (Z1-9) & $250 * 350$ & 1.4 & $400 * 500$ & $6 @ 50$ & $6 @ 100$ & 8@100 & 9 \\
\hline 2nd group (J1-9) & $320 * 450$ & 1.3 & $400 * 500$ & 8@50 & 8@100 & 10@100 & 9 \\
\hline 3 rd group (M1-9) & $286 * 400$ & 1.6 & $400 * 500$ & 8@50 & 8@100 & 10@100 & 9 \\
\hline
\end{tabular}
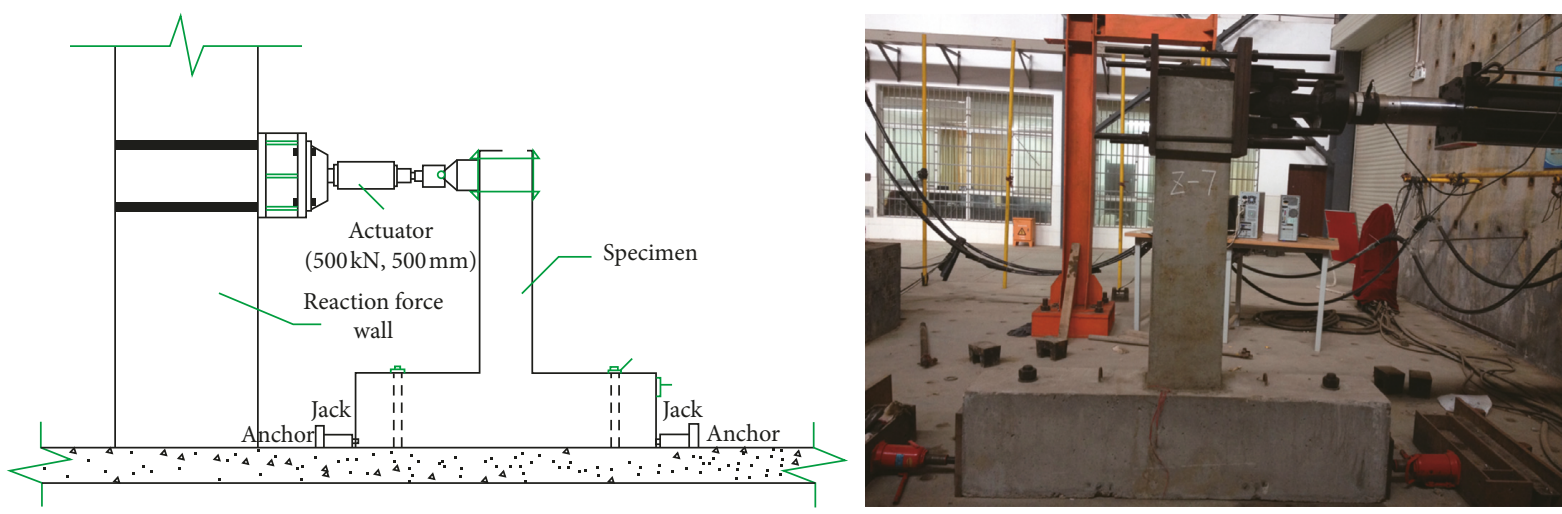

FIgURE 4: Loading system.

where $H$ is the length of the arm of force. The uniformly distributed load on the top of the test member was converted to the equivalent concentrated load when determining $H$.

Using the graph multiplication method, the yield displacement can be obtained as

$$
\Delta=\frac{F_{\mathrm{y}} H^{3}}{3 B_{\mathrm{s}}},
$$

where $B_{\mathrm{s}}$ is the short-term stiffness of the test member, computed as 


$$
B_{\mathrm{s}}=\frac{E_{\mathrm{s}} A_{\mathrm{s}} h_{0}^{2}}{1.15 \psi+0.2+\left(6 \alpha_{\mathrm{E}} \rho / 1+3.5 \gamma_{\mathrm{f}}^{\prime}\right)},
$$

where $E_{\mathrm{s}}$ is the reinforced elastic modulus, $\alpha_{\mathrm{E}}$ is the ratio of the reinforced elastic modulus and modulus of elasticity of concrete, $\rho$ is the longitudinal tensile reinforcement ratio, $r_{\mathrm{f}}^{\prime}$ is the ratio of the compressive flange and web section of the effective area, and $\psi$ is the longitudinal uneven coefficient of tensile steel bar strain between cracks:

$$
\begin{aligned}
\psi & =1.1-\frac{0.65 f_{\mathrm{tk}}}{\rho_{\mathrm{te}} \sigma_{\mathrm{sk}}}, \\
\rho_{\mathrm{te}} & =\frac{A_{\mathrm{s}}}{0.5 b h_{0}}, \\
\sigma_{\mathrm{sk}} & =\frac{M_{\mathrm{k}}}{0.87 h_{0}}, \\
M_{\mathrm{k}} & =f_{\mathrm{yk}} A_{\mathrm{s}}\left(h_{0}-a_{\mathrm{s}}^{\prime}\right) .
\end{aligned}
$$

The yield load and yield displacement results of each group's specimens are shown in Table 2.

3.3. Loading Program. Ground motion during an earthquake is a complex irregular vibration. It is difficult to study the structural damage process under an earthquake load because of the load's irregularity, which encompasses various vibration amplitudes and frequencies [28]. According to Fourier transform theory, any complex function can be regarded as an infinite superposition of a series of harmonic functions with a single amplitude and period [29, 30]. Based on that, we can study the structural damage process under a harmonic load, and this is the foundation of studying the structural damage process under an earthquake load. In this experiment, we applied a harmonic load (displacement control) to test members; thus, it is easy to analyze the effect of the loading period and loading amplitude on a test member's damage. The plan for applying the harmonic load (displacement control) is shown in Table 3. For the same group of test members (same strength, stiffness, and size), the period and amplitude of the harmonic load were changed, and the effect of its period and amplitude on the natural frequency change of each test member during the damage process was studied. Under earthquake loading, test members will enter the plastic state, so the amplitude of loading was set to be larger than the test members' yield displacement, as shown in Table 2.

\section{Experimental Observations and Failure Modes}

4.1. Damage Process Observations. Each group of test members had a different strength, stiffness, and size, so their damage processes differed. However, their damage processes could generally be divided into four stages.

In the first stage, the bottom of a test member cracked at the first loading cycle; cracks then developed rapidly and soon passed throughout the front and back surface of the test
TABLE 2: Yield loads and yield displacements.

\begin{tabular}{lccc}
\hline Specimen & $\begin{array}{c}\text { Yield } \\
\text { moment } \\
(\mathrm{N} \cdot \mathrm{mm})\end{array}$ & $\begin{array}{c}\text { Yield } \\
\text { load }(\mathrm{N})\end{array}$ & $\begin{array}{c}\text { Yield } \\
\text { displacement } \\
(\mathrm{mm})\end{array}$ \\
\hline First group & $115.3 \times 10^{6}$ & $82.2 \times 10^{3} / 60$ & 8.7 \\
Second group & $235.9 \times 10^{6}$ & $148.7 \times 10^{3} / 130$ & 15.5 \\
Third group & $187.3 \times 10^{6}$ & $122.1 \times 10^{3} / 110$ & 11.8 \\
\hline
\end{tabular}

TABLE 3: Harmonic vibration loading scheme.

\begin{tabular}{lccc}
\hline Period & & Amplitude & \\
& $A=30 \mathrm{~mm}$ & $A=24 \mathrm{~mm}$ & $A=18 \mathrm{~mm}$ \\
\hline$T=1.875 \mathrm{~s}$ & $\mathrm{Z}-1 / \mathrm{J}-1 / \mathrm{M}-1$ & $\mathrm{Z}-4 / \mathrm{J}-4 / \mathrm{M}-4$ & $\mathrm{Z}-7 / \mathrm{J}-7 / \mathrm{M}-7$ \\
$T=2.4 \mathrm{~s}$ & $\mathrm{Z}-2 / \mathrm{J}-2 / \mathrm{M}-2$ & $\mathrm{Z}-5 / \mathrm{J}-5 / \mathrm{M}-5$ & $\mathrm{Z}-8 / \mathrm{J}-8 / \mathrm{M}-8$ \\
$T=3.0 \mathrm{~s}$ & $\mathrm{Z}-3 / \mathrm{J}-3 / \mathrm{M}-3$ & $\mathrm{Z}-6 / \mathrm{J}-6 / \mathrm{M}-6$ & $\mathrm{Z}-9 / \mathrm{J}-9 / \mathrm{M}-9$ \\
\hline
\end{tabular}

member. Test data showed that a test member's carrying capacity decreased rapidly. This stage corresponds to the first 20 cycles of loading for the first group of test members, the first 10 cycles for the second group, and the first 15 cycles for the third group.

In the second stage, cracks further developed and the number of cracks increased obviously, and the concrete was partially spalled. Concrete and reinforcement still worked together to bear the load. Reinforcements yielded, and a plastic hinge was formed at the bottom of the test members. The rate of damage increased, and the carrying capacity decreased quickly. This stage corresponds to 20-60 cycles of loading for the first group of test members, 10-40 cycles for the second group, and 15-50 cycles for the third group.

In the third stage, the concrete between the main cracks crushed severely, and many concrete blocks spalled. Concrete no longer bore a load, so the load was borne solely by the steel. The plastic hinge zone further expanded. This stage corresponds to 60-100 cycles of loading for the first group of specimens, 40-70 cycles for the second group, and 50-80 cycles for the third group.

In the fourth stage, the test member was destroyed completely, a large number of concrete blocks spalled, and the steel bars were exposed. The load applied to a test member maintained a certain low value and varied little. Test members' destruction zones concentrated at the bottom. In this stage, the height of the destruction zone (plastic hinge region), which could be clearly observed, was about $35 \mathrm{~cm}$ for the first group of specimens, $20 \mathrm{~cm}$ for the second group, and $27 \mathrm{~cm}$ for the third group.

Figure 5 shows the damage or failure modes of test member Z-2 in each stage. Its damage process was typical. Figures 6 and 7 show the damage or failure modes of test members J-3 and M-5, respectively.

4.2. Failure Modes. A specimen's failure mode is important for the study of its frequency change during the damage process, because different failure modes indicate different damage processes. Research shows that RC columns generally have three types of failure mode: bending, shear, and 


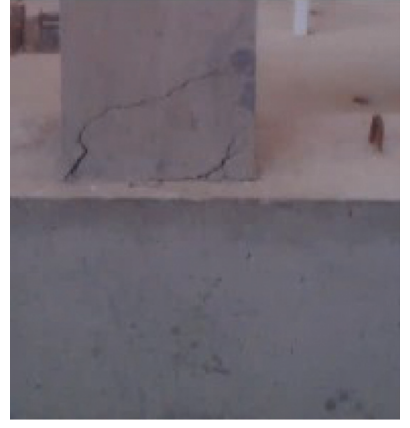

(a)

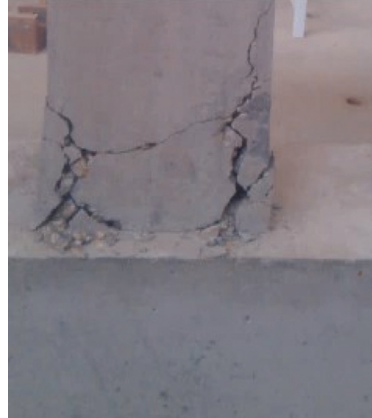

(b)

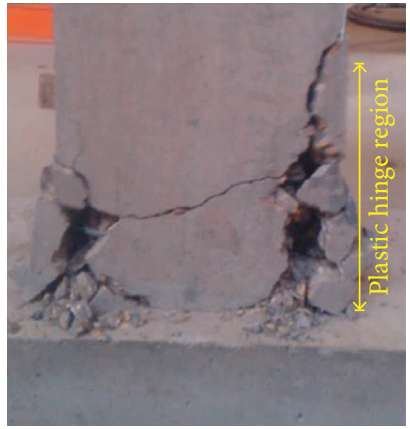

(c)

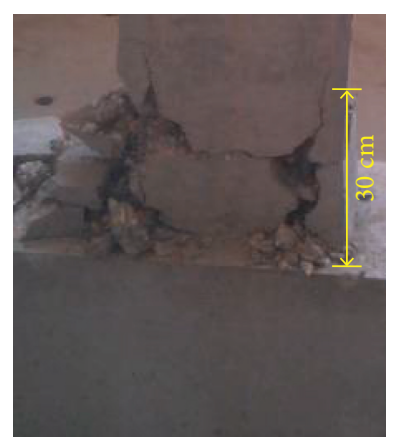

(d)

Figure 5: Damage of Z-2 at (a) 10th loading cycle; (b) 30th loading cycle; (c) 70th loading cycle; (d) 100th loading cycle.

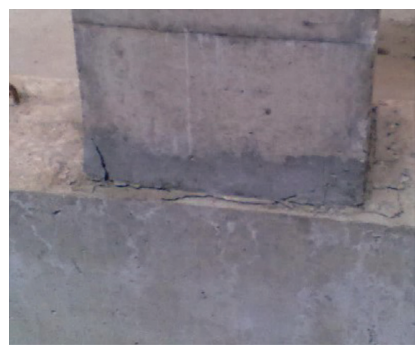

(a)

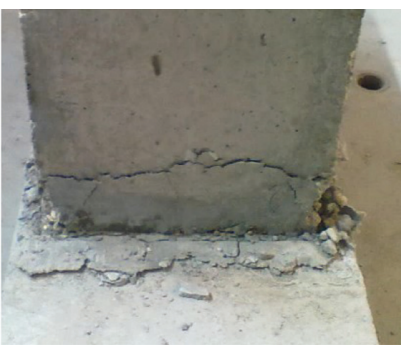

(b)

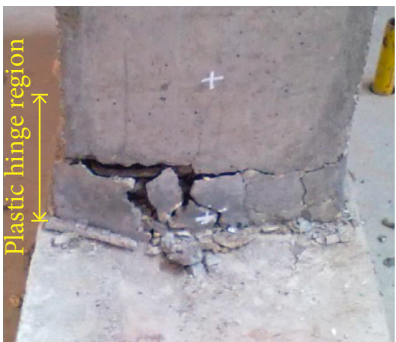

(c)

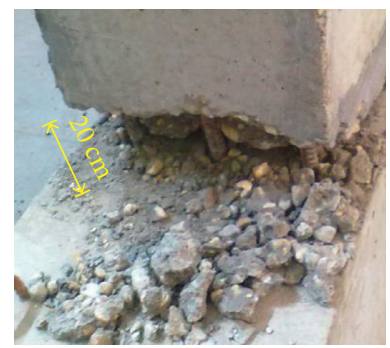

(d)

Figure 6: Damage of J-3 at (a) 10th loading cycle; (b) 30th loading cycle; (c) 70th loading cycle; (d) 100th loading cycle.

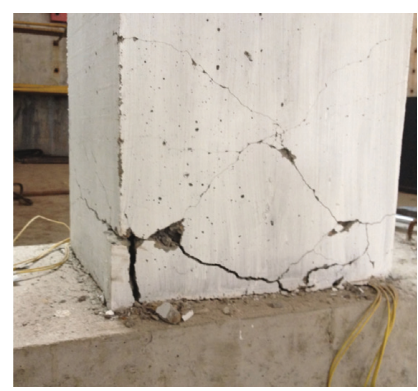

(a)

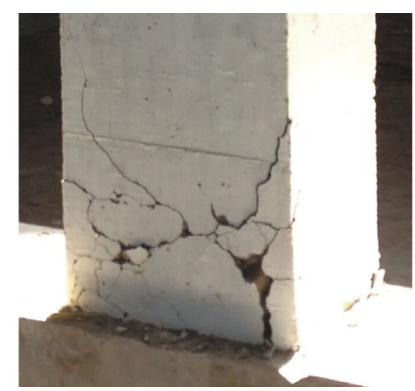

(b)

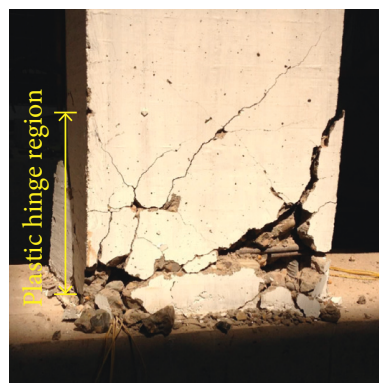

(c)

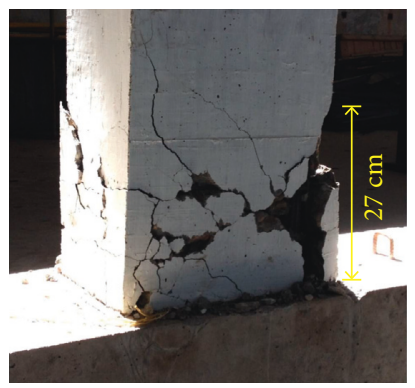

(d)

FIgUre 7: Damage of M-5 at (a) 10th loading cycle; (b) 30th loading cycle; (c) 70th loading cycle; (d) 100th loading cycle.

bending shear [31, 32]. Bending failure occurs when a specimen's axial compression ratio is small, its shear span ratio is large, and its reinforcement is reasonable. Bending deformation occurs when primary and longitudinal reinforcements yield at failure. Shear failure occurs when the axial compression ratio is large and the shear span ratio and stirrup ratio are small. Shear deformation occurs when primary and longitudinal reinforcements do not yield at failure. Bending shear failure occupies an area between bending failure and shear failure. First, longitudinal reinforcements yield and a plastic hinge forms at the bottom of the column, then the shear bearing capacity decreases due to the development of shear diagonal cracks. Finally, the stirrup in the plastic hinge area yields and shear failure occurs.

For the convenience of study, the failure modes of all test members should be the same. To induce bending failure in all the test members, an axial force was not applied to test members, i.e., the axial compression ratios were zero. Large shear span ratios were adopted, as shown in Table 4. It was observed in the experiment that all test members' roots generated a horizontal main crack and the width of cracks increased as number of loading cycles increased. The longitudinal reinforcements yielded, and the compressive concrete crushed and spalled. The stirrup did not yield at failure. Those are the typical bending failure characteristics, so the failure mode of all test members in all three groups was bending failure.

\section{Hysteretic Curves}

Hysteretic curves reflect a test member's strength degradation, stiffness degradation, and energy dissipation [33, 34]. 
TABle 4: Specimens' axial compression ratios, shear span ratios, and stirrup ratios.

\begin{tabular}{lccc}
\hline Specimen & \multicolumn{3}{c}{ Item } \\
& $\begin{array}{c}\lambda / \text { axial compression } \\
\text { ratio }\end{array}$ & $\begin{array}{c}n / \text { shear } \\
\text { span ratio }\end{array}$ & $\begin{array}{c}\beta_{\mathrm{v}} / \text { stirrup } \\
\text { ratio }(\%)\end{array}$ \\
\hline First group & 0 & 3.76 & 0.7 \\
Second group & 0 & 2.92 & 0.85 \\
Third group & 0 & 3.29 & 0.96 \\
\hline
\end{tabular}

Figure 8 shows typical hysteretic curves of some test members. These can all be seen to have the following characteristics. (1) Because the loading amplitude was set larger than the specimens' yield displacement, they yielded at the first loading cycle. Hysteretic curves clearly show the yield load and yield displacement of specimens. For example, Figure 8 shows that specimen Z-3's yield load and yield displacement were about $68 \mathrm{kN}$ and $10 \mathrm{~mm}$, respectively. (2) The average stiffness (slope of line connecting diagonal peak points in the same load cycle) decreased as number of loading cycles increased. (3) In each hysteretic curve, the position of peak points became lower as number of loading cycles increased, indicating a decrease in a specimen's bearing capacity as number of loading cycles increased. (4) In the early stage of loading, the specimens' stiffness and bearing capacity decreased quickly, indicating rapid damage. In the late loading stage, stiffness and bearing capacity degradation occurred slowly. (5) Overall, the hysteretic curves had full shapes and had no significant pinch phenomenon. These curve characteristics also show that the specimens failed due to bending.

Figure 8 shows that the area enclosed by the hysteretic curves is largest in the first line (loading displacement/ amplitude is $30 \mathrm{~mm}$ ), somewhat smaller in the second line (loading displacement/amplitude is $24 \mathrm{~mm}$ ), and significantly smaller in the third line (loading displacement/amplitude is $18 \mathrm{~mm}$ ). This indicates that the loading displacement has an obvious impact on the hysteretic curve. The larger the loading displacement, the fuller the hysteretic curve and the greater the energy dissipation capacity. However, a comparison of the hysteretic curves under different loading periods shows that the impact of the loading period on the hysteretic curve is not obvious.

\section{Impact of Load and Displacement on a Specimen's Natural Frequency}

We analyzed the impact of load and displacement on a test member's natural frequency and determined a function of the three variables. This function enabled us to accurately obtain the real-time value of a test member's natural frequency.

During reciprocating movement, a test member's stiffness changed continuously with time because of damage. Stiffness is a function of the time $t$ and is denoted by $k(t)$. The load applied to a test member and the displacement of the test member are also functions of time; they are denoted, respectively, by $F(t)$ and $y(t)$. These three quantities are related by the definition of stiffness,

$$
F(t)=y(t) k(t)
$$

Equation (6) applies from the elastic stage through the plastic stage. After entering a plastic state, the force causing the same displacement continues to fall as the structural damage develops, which can be seen from Equation (6). The function $k(t)$ is generalized stiffness. is [35]

The structural natural frequency (circular frequency)

$$
\omega^{2}=\frac{k}{m} .
$$

A test member's quality, $m$, changed negligibly during loading and damage, so it was regarded as constant. The natural frequency changed during the damage process, so it is a function of time $t$, denoted by $\omega(t)$. Therefore, Equation (7) could be written as

$$
[\omega(t)]^{2}=\frac{k(t)}{n} .
$$

By substituting Equation (6) into Equation (8), it was found that

$$
\omega(t)=\sqrt{\frac{k(t)}{m}}=\sqrt{\frac{F(t)}{y(t) m}} .
$$

Equation (9) indicates that at any moment $t$, if a test member's displacement $y(t)$ and load $F(t)$ are known, the natural frequency $\omega(t)$ can be calculated.

\section{Analysis of a Specimen's Natural Frequency Change}

According to the loading plan (Table 3), natural frequency change processes under different loading periods and amplitudes can easily be compared. In this way, the impact of the loading period and amplitude on a test member's natural frequency change can be investigated.

7.1. Frequency Change Curves under Different Loading Periods. The measured data of test members Z-1, Z-2, Z-3, J-1, J-2, J-3, M-1, M-2, and M-3 were analyzed. Their loading amplitudes were all $30 \mathrm{~mm}$, but their loading periods varied. The loading displacement $y(t)$ was set to $30 \mathrm{~mm}$, and $F(t)$ was set to the load corresponding to that displacement. The corresponding natural frequency was calculated using Equation (9). Next, we drew the curves in a coordinate system whose abscissa was the number of loading cycles and whose ordinate was the test member's natural frequency, as shown in Figures 9(a)-9(c). These curves show the frequency-change processes of the test members in each group. The fitting equation of each curve was obtained by curve-fitting analysis.

Similarly, curves of the inherent frequency versus the number of loading cycles were obtained for test members Z-4, Z-5, Z-6, J-4, J-5, J-6, M-4, M-5, and M-6, whose loading amplitudes were all $24 \mathrm{~mm}$, as shown in Figures 9(d)-9(f). The curves of test members Z-7, Z-8, Z-9, J-7, J-8, J-9, M-7, M-8, and M-9, whose loading amplitudes were all $18 \mathrm{~mm}$, 

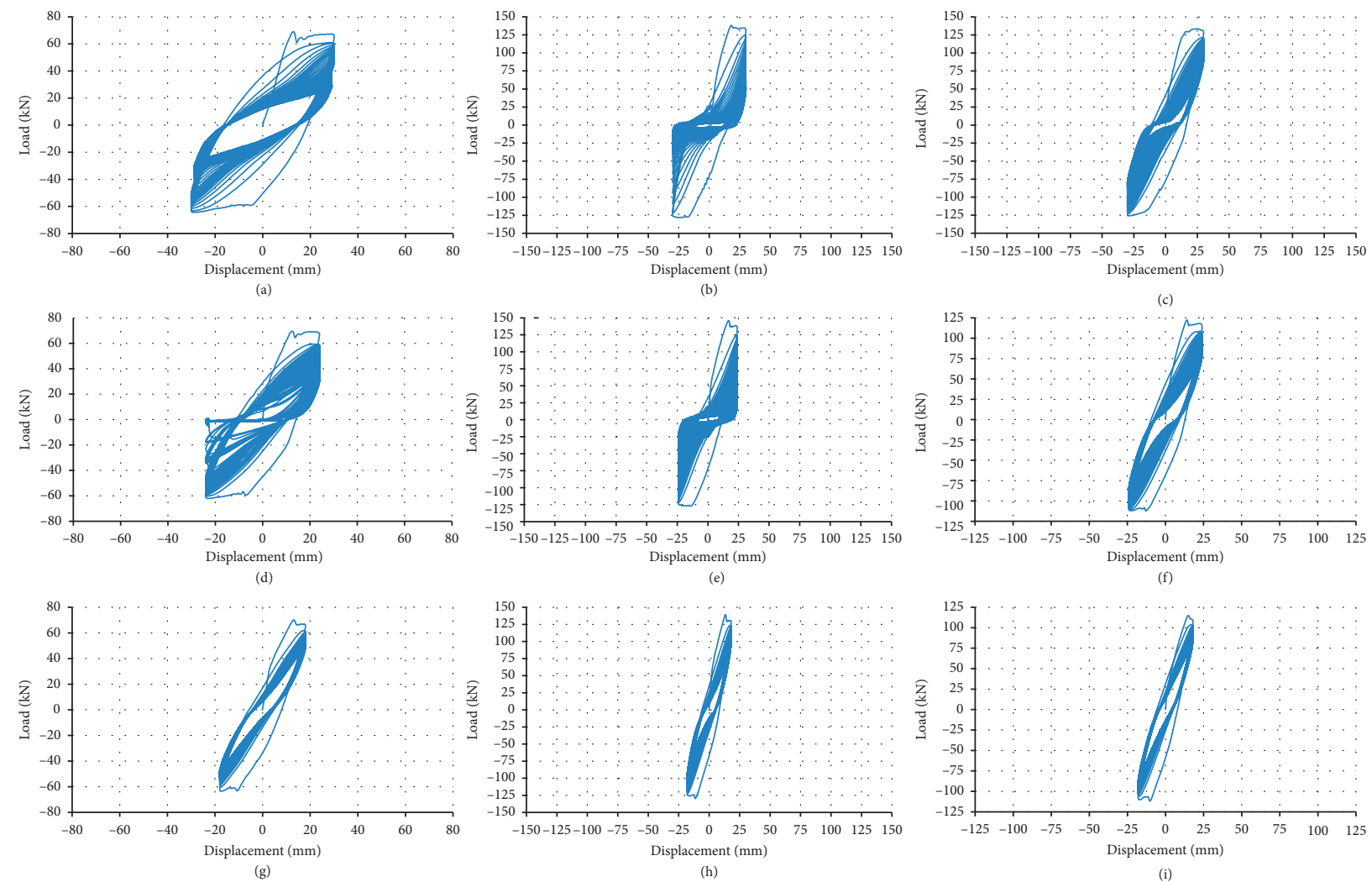

Figure 8: Typical hysteretic curves of some test members. (a) Z-1. (b) J-1. (c) M-2. (d) Z-4. (e) J-4. (f) M-4. (g) Z-7. (h) J-7. (i) M-8.

were also obtained, as shown in Figures 9(g)-9(i). In the figure, the fitting equation of each curve is given. Figure 9 shows that the structure frequencies trended downward with the structural damage. Additionally, most test members' frequencies decreased faster in the early stage of loading, indicating faster damage at the early loading stage. Test members' frequencies decreased more slowly in the late loading stage.

It can be seen that the impact of the loading period (that is, the speed of a test member's reciprocating motion) on the damage process is mainly reflected in the speed of damage. Thus, a relationship between the loading period and the damage speed was thought to exist. For further analysis, we obtained the speed of the damage process of each test member. We determined a test member's damage rate function by taking the first derivative of the fitting equation of the frequency-change curve, as shown in Table 5. It was necessary to analyze a set of test members with the same amplitudes, such as Z-1, Z-2, and Z-3. In the $3 \mathrm{D}$ coordinate system, we drew the space points with coordinates $(V, N, T)$, where $V$ is the damage rate, $N$ is the number of loading cycles, and $T$ is the loading period. Then we used MATLAB to fit the data, and we obtained the fitting curve surface shown in Figure 10(a), along with the fitting equation, $(V, N, T)=P_{20} N^{2}+P_{11} N T+P_{02} T^{2}+$ $P_{10} N+P_{01} T+P_{00}$, where $P_{00}=-6, P_{10}=0.024, P_{01}=4.5$, $P_{20}=-6.2 e-8, P_{11}=-0.01$, and $P_{02}=-0.88$. The equation indicates the quantitative effect of the loading period $T$ on the damage rate $V$. We similarly obtained fitting curve surfaces for the damage rate $V$, number of loading cycles $N$, and loading period $T$ of each test member, as shown in Figures 10(b)-10(i). The equations of the curved surfaces have a uniform expression,

$$
V(N, T)=P_{20} N^{2}+P_{11} N T+P_{02} T^{2}+P_{10} N+P_{01} T+P_{00} .
$$

Equation (10) relates the damage rate $V$, loading period $T$, and number of loading cycles $N$. The coefficients $P_{i j}$ in Equation (10) are listed in Table 6.

We drew the following conclusions from Equation (10) and its coefficients. The quadratic term's coefficient of number of loading cycles $N$ is very small, indicating a basically positive, proportional, linear relationship between the loading cycle and damage rate. The coefficient of the quadratic term of the loading period $T$ is relatively large (the same order of magnitude as the linear term's coefficient); hence, the load period has a quadratic effect on the damage rate. We also see that the first group of test members has larger frequency changes than the second group. This shows that the greater an RC member's stiffness, the greater its natural frequency change.

7.2. Frequency Change Curves under Different Loading Amplitudes. The test members were regrouped according to their loading periods; that is, Z-2, Z-5, Z-8, J-2, J-5, J-8, M-2, $M-5$, and $M-8$ were sorted into a group whose loading period was $2.4 \mathrm{~s} ; \mathrm{Z}-1, \mathrm{Z}-4, \mathrm{Z}-7, \mathrm{~J}-1, \mathrm{~J}-4, \mathrm{~J}-7, \mathrm{M}-1, \mathrm{M}-4$, and M-7 were 

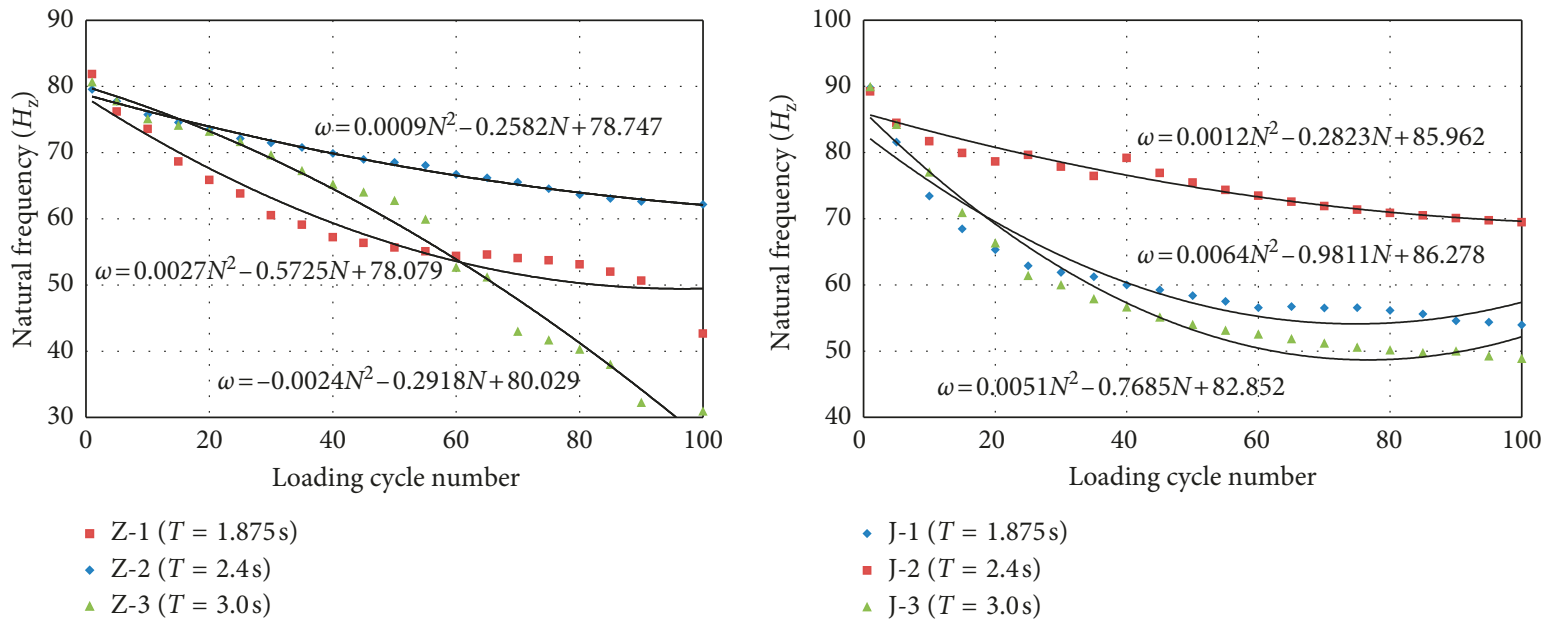

(a)

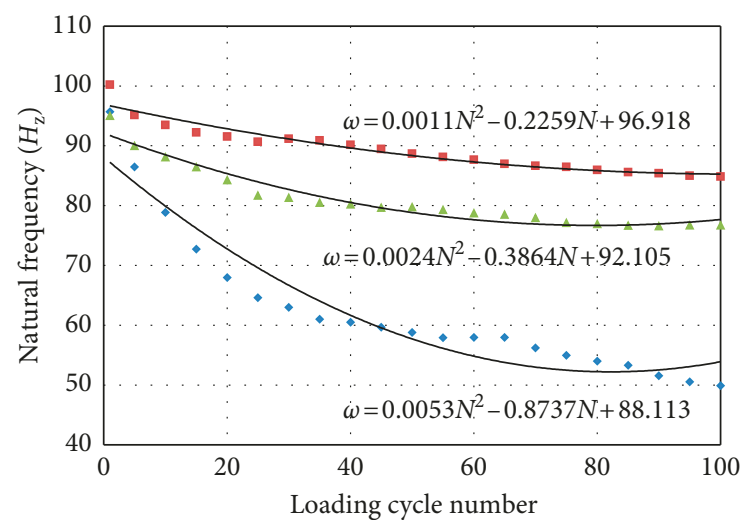

(b)

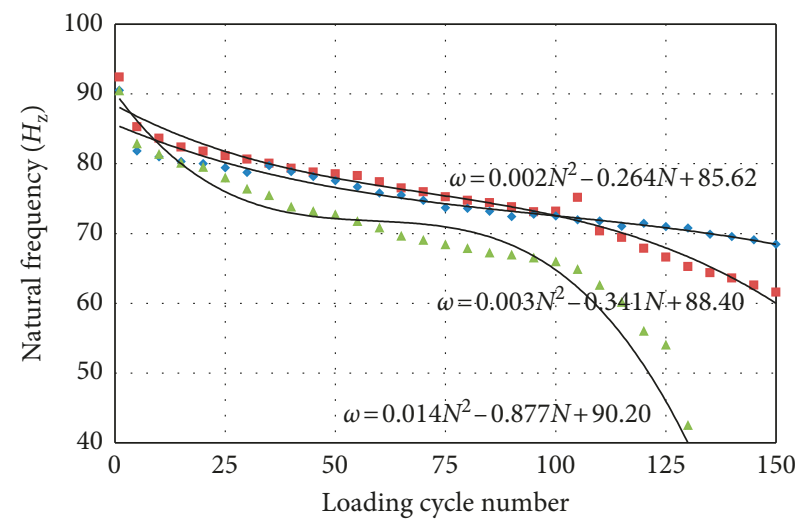

- $\mathrm{M}-1(T=1.875 \mathrm{~s})$

- $\mathrm{M}-2(T=2.4 \mathrm{~s})$

$$
\begin{aligned}
& \mathrm{Z}-4(T=1.875 \mathrm{~s}) \\
& \text { - Z-5 }(T=2.4 \mathrm{~s}) \\
& \text { ¿ } \mathrm{Z}-6(T=3.0 \mathrm{~s})
\end{aligned}
$$

(d)
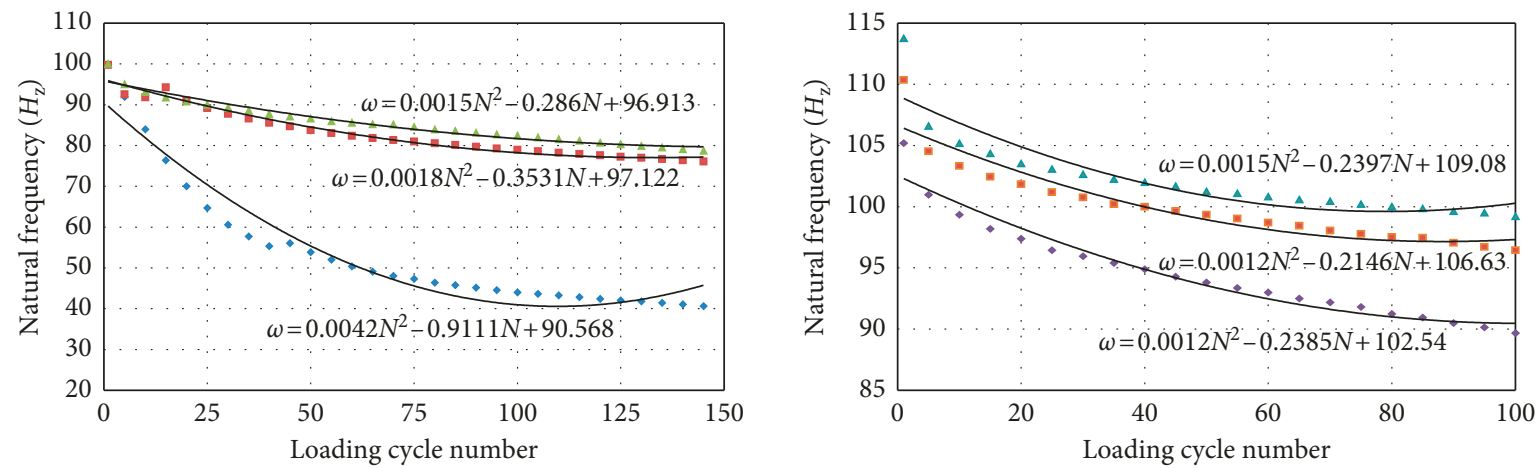

- $\mathrm{J}-4(T=1.875 \mathrm{~s})$

- $\mathrm{J}-5(T=2.4 \mathrm{~s})$

- $\mathrm{M}-4(T=1.875 \mathrm{~s})$

$\triangle \mathrm{M}-5(T=2.4 \mathrm{~s})$

- M-6 $(T=3.0 \mathrm{~s})$

(e)

(f)

Figure 9: Continued. 

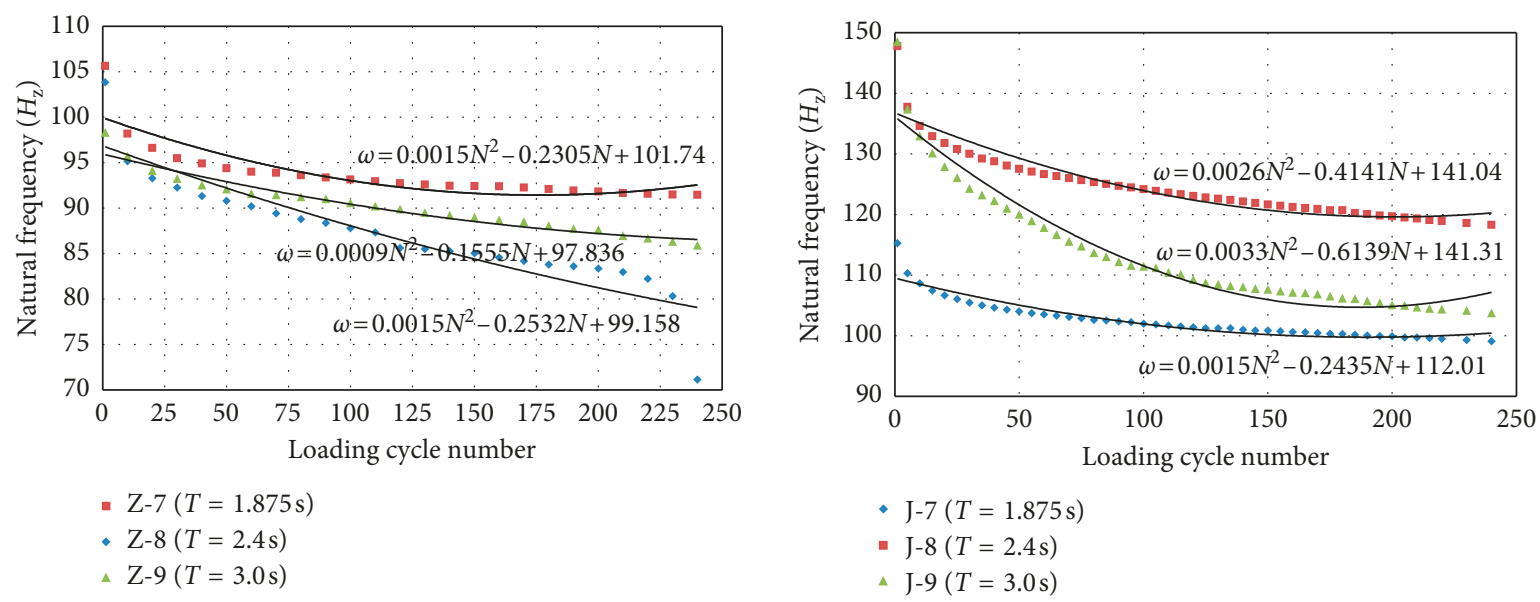

(g)

(h)

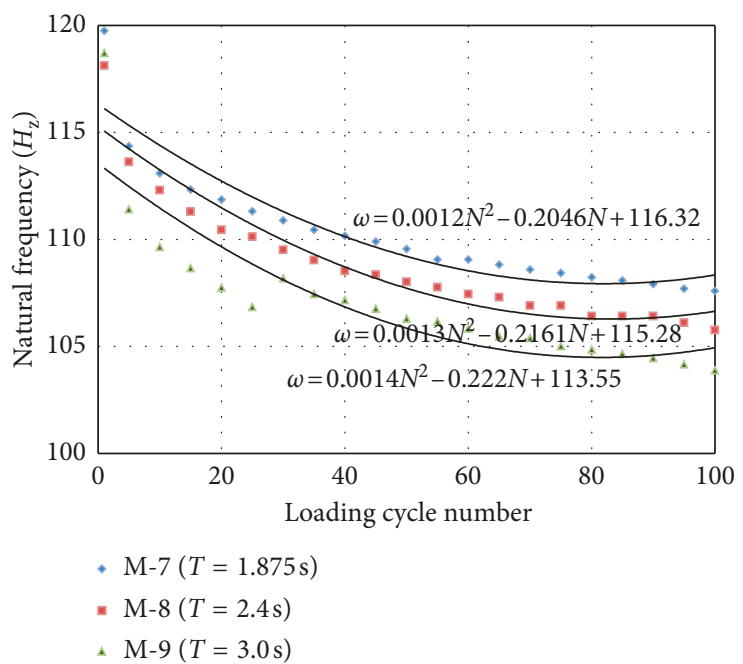

(i)

Figure 9: Natural frequency-change curves. (a) Z-1, Z-2, Z-3. (b) J-1, J-2, J-3. (c) M-1, M-2, M-3. (d) Z-4, Z-5, Z-6. (e) J-4, J-5, J-6. (f) M-4, M-5, M-6. (g) Z-7, Z-8, Z-9. (h) J-7, J-8, J-9. (i) M-7, M-8, M-9.

sorted into a group whose loading period was $1.875 \mathrm{~s}$; and Z-3, Z67, Z-9, J-3, J-6, J-9, M-3, M-6, and M-9 were sorted into a group whose loading period was $3.0 \mathrm{~s}$. The natural frequency change curves of these three groups are shown in Figures 11(a)-11(i). When the loading amplitude was greater, the test member's natural frequency decreased faster and the attenuation was greater.

The fitting equations of the curves and damage rate equations can be seen in Table 5 . The specimens were regrouped according to loading period; sets of test members with the same period were selected. MATLAB was used to fit the 3D data of $V, N$, and $T$ (defined above) to obtain the fitting curve surfaces shown in Figure 12. The fitting equation was obtained as

$V(A, N)=P_{20} A^{2}+P_{11} A N+P_{02} N^{2}+P_{10} A+P_{01} N+P_{00}$,

whose coefficients $P_{i j}$ are listed in Table 7. Equation (11) relates the damage rate $V$, loading amplitude $A$, and number of loading cycles $N$.
Figure 12 shows that the fitting surfaces $V(A, N)$ are close to a plane, and the data in Table 7 show that the quadratic term coefficients $P_{20}, P_{11}$, and $P_{02}$ in the fitting equation $V(A, N)$ are very small. This indicates that the loading amplitude and number of loading cycles have a basically linear impact on the damage rate.

7.3. Impact of Loading Period and Amplitude on Natural Frequency Change. The previous section only analyzed the individual impact of the loading period or loading amplitude on a test member's frequency change. We now examine how the loading period and loading amplitude work together to affect a test member's frequency change, so as to find the natural frequency-change characteristics of an RC member under an arbitrary harmonic vibration.

The change characteristics of a test member's frequency can be expressed as a function of one variable, $\omega(N)$, where the independent variable is the number of loading cycles $N$. Therefore, after considering the loading period and amplitude, we chose to express the change characteristics of a test 
TABle 5: Frequency change equations and damage rate equations of test members.

\begin{tabular}{|c|c|c|c|}
\hline \multirow{2}{*}{\multicolumn{2}{|c|}{ Specimen category }} & \multicolumn{2}{|c|}{ Equation } \\
\hline & & Frequency change equation & Damage rate equation \\
\hline$A=30 \mathrm{~mm}$ & $\begin{array}{c}\mathrm{Z}-1(T=1.875 \mathrm{~s}) \\
\mathrm{Z}-2(T=2.4 \mathrm{~s}) \\
\mathrm{Z}-3(T=3.0 \mathrm{~s}) \\
\mathrm{J}-1(T=1.875 \mathrm{~s}) \\
\mathrm{J}-2(T=2.4 \mathrm{~s}) \\
\mathrm{J}-3(T=3.0 \mathrm{~s}) \\
\mathrm{M}-1(T=1.875 \mathrm{~s}) \\
\mathrm{M}-2(T=2.4 \mathrm{~s}) \\
\mathrm{M}-3(T=3.0 \mathrm{~s})\end{array}$ & $\begin{array}{c}\omega=0.0027 N^{2}-0.5725 N+78.079 \\
\omega=0.0009 N^{2}-0.2582 N+78.747 \\
\omega=-0.0024 N^{2}-0.2918 N+80.029 \\
\omega=0.0051 N^{2}-0.7685 N+82.852 \\
\omega=0.0012 N^{2}-0.2823 N+85.962 \\
\omega=0.0064 N^{2}-0.9811 N+86.278 \\
\omega=0.005 N^{2}-0.873 N+88.11 \\
\omega=0.001 N^{2}-0.225 N+96.91 \\
\omega=0.002 N^{2}-0.386 N+92.10\end{array}$ & $\begin{array}{c}V=2 * 0.0027 N-0.5725 \\
V=2 * 0.0009 N-0.2582 \\
V=2 *(-0.0024) N-0.2918 \\
V=2 * 0.0051 N-0.7685 \\
V=2 * 0.0012 N-0.2823 \\
V=2 * 0.0064 N-0.9811 \\
V=2 * 0.005 N-0.873 \\
V=2 * 0.001 N-0.225 \\
V=2 * 0.002 N-0.386\end{array}$ \\
\hline$A=24 \mathrm{~mm}$ & $\begin{array}{c}\text { Z-4 }(T=1.875 \mathrm{~s}) \\
\text { Z-5 }(T=2.4 \mathrm{~s}) \\
\text { Z-6 }(T=3.0 \mathrm{~s}) \\
\text { J-4 }(T=1.875 \mathrm{~s}) \\
\text { J-5 }(T=2.4 \mathrm{~s}) \\
\text { J-6 }(T=3.0 \mathrm{~s}) \\
\text { M-4 }(T=1.875 \mathrm{~s}) \\
\text { M-5 }(T=2.4 \mathrm{~s}) \\
\text { M-6 }(T=3.0 \mathrm{~s})\end{array}$ & $\begin{array}{c}\omega=0.003 N^{2}-0.341 N+88.40 \\
\omega=0.002 N^{2}-0.264 N+85.62 \\
\omega=0.014 N^{2}-0.877 N+90.20 \\
\omega=0.0078 N^{2}-1.2601 N+95.533 \\
\omega=0.0018 N^{2}-0.3531 N+97.122 \\
\omega=0.0015 N^{2}-0.286 N+96.913 \\
\omega=0.001 N^{2}-0.238 N+102.5 \\
\omega=0.001 N^{2}-0.239 N+109.0 \\
\omega=0.001 N^{2}-0.214 N+106.6\end{array}$ & $\begin{array}{c}V=2 * 0.003 N-0.341 \\
V=2 * 0.002 N-0.264 \\
V=2 * 0.0014 N-0.877 \\
V=2 * 0.0078 N-1.2601 \\
V=2 * 0.0018 N-0.3531 \\
V=2 * 0.0015 N-0.286 \\
V=2 * 0.001 N-0.238 \\
V=2 * 0.001 N-0.239 \\
V=2 * 0.001 N-0.214\end{array}$ \\
\hline$A=18 \mathrm{~mm}$ & $\begin{array}{c}\text { Z-7 }(T=1.875 \mathrm{~s}) \\
\text { Z-8 }(T=2.4 \mathrm{~s}) \\
\text { Z-9 }(T=3.0 \mathrm{~s}) \\
\text { J-7 }(T=1.875 \mathrm{~s}) \\
\text { J-8 }(T=2.4 \mathrm{~s}) \\
\text { J-9 }(T=3.0 \mathrm{~s}) \\
\text { M-7 }(T=1.875 \mathrm{~s}) \\
\text { M-8 }(T=2.4 \mathrm{~s}) \\
\text { M-9 }(T=3.0 \mathrm{~s})\end{array}$ & $\begin{array}{c}\omega=0.0015 N^{2}-0.2305 N+101.74 \\
\omega=0.0015 N^{2}-0.2532 N+99.158 \\
\omega=0.0009 N^{2}-0.1555 N+97.336 \\
\omega=0.0012 N^{2}-0.2003 N+98.11 \\
\omega=0.0011 N^{2}-0.255 N+87.926 \\
\omega=0.0019 N^{2}-0.3883 N+86.874 \\
\omega=0.001 N^{2}-0.204 N+116.3 \\
\omega=0.001 N^{2}-0.216 N+115.2 \\
\omega=0.001 N^{2}-0.222 N+113.5\end{array}$ & $\begin{array}{c}V=2 * 0.0015 N-0.2305 \\
V=2 * 0.0015 N-0.2532 \\
V=2 * 0.0009 N-0.1555 \\
V=2 * 0.0012 N-0.2003 \\
V=2 * 0.0011 N-0.255 \\
V=2 * 0.0019 N-0.3883 \\
V=2 * 0.001 N-0.204 \\
V=2 * 0.001 N-0.216 \\
V=2 * 0.001 N-0.222\end{array}$ \\
\hline
\end{tabular}

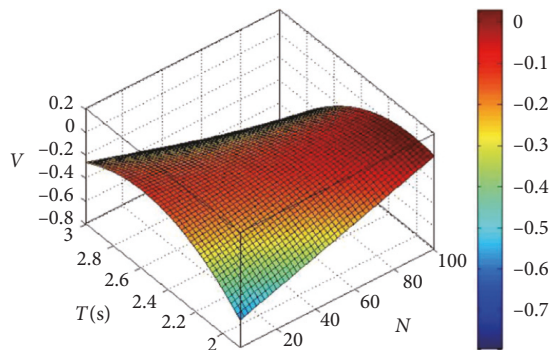

(a)

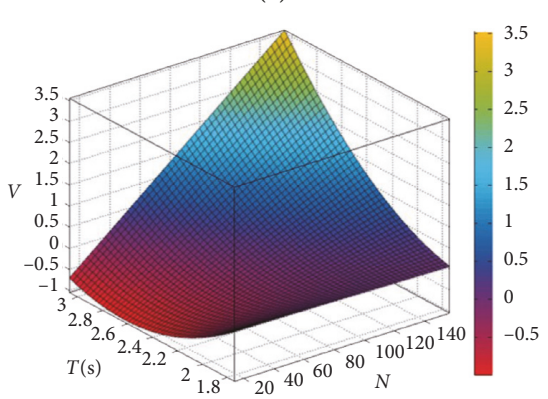

(d)

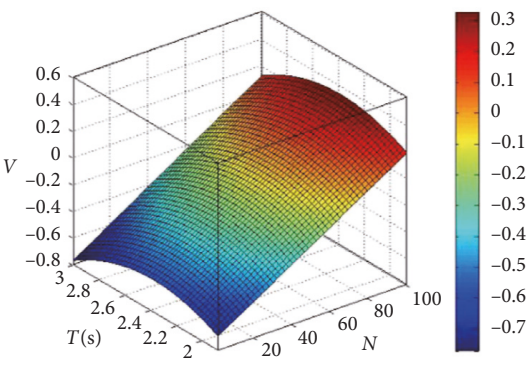

(b)

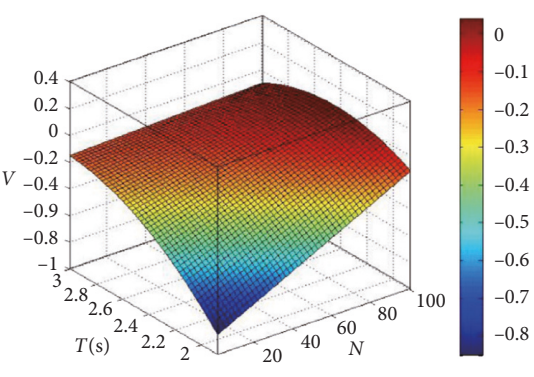

(e)

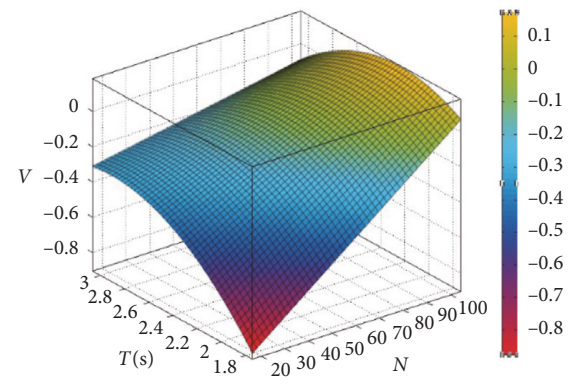

(c)

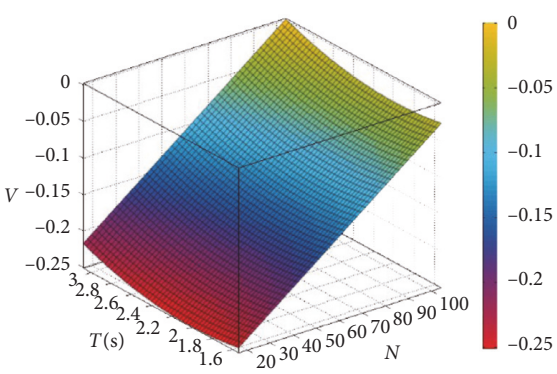

(f)

Figure 10: Continued. 


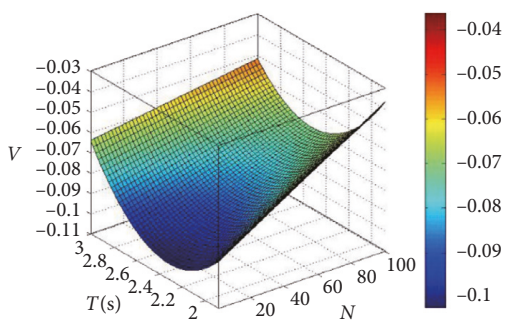

(g)

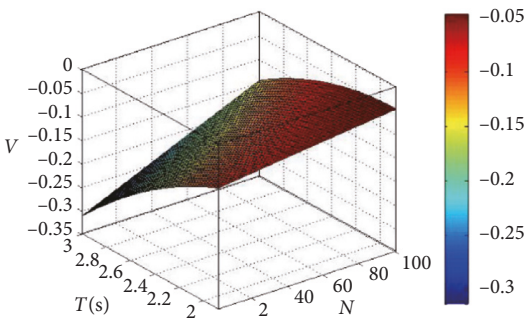

(h)

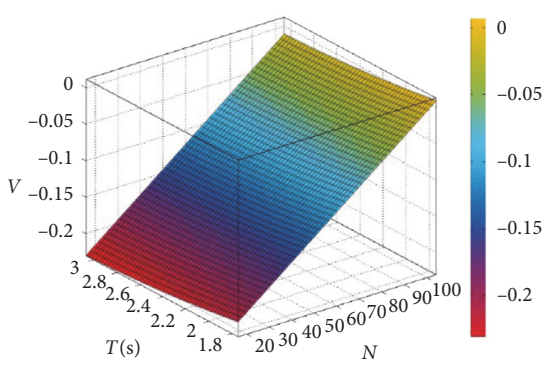

(i)

Figure 10: Damage-rate fitted surfaces of $(V)$, (N), (T). (a) Z-1, Z-2, Z-. (b) J-1, J-2, J-3. (c) M-1, M-2, M-3. (d) Z-4, Z-5, Z-6. (e) J-4, J-5, J-6. (f) M-4, M-5, M-6. (g) Z-7, Z-8, Z-9. (h) J-7, J-8, J-9. (i) M-7, M-8, M-9.

Table 6: Coefficients of function of $V(N, T)$.

\begin{tabular}{lccccc}
\hline \multirow{2}{*}{ Test members } & \multicolumn{5}{c}{ Coefficients of the function } \\
& $P_{00}$ & $P_{10}$ & $P_{01}$ & $P_{20}$ & $P_{11}$ \\
\hline Z-1, Z-2, Z-3 & -6 & 0.024 & 4.5 & $-6.2 e-8$ & -0.01 \\
J-1, J-2, J-3 & -3.6 & 0.0088 & 2.59 & $-3.887 e-7$ & 0.0001 \\
M-1, M-2, M-3 & -1.476 & 0.0113 & 0.84 & $-1.2 e-9$ & -0.003 \\
Z-4, Z-5, Z-6 & -1.6 & 0.012 & 1.1 & $-2.43 e-7$ & -0.0059 \\
J-4, J-5, J-6 & -4.735 & 0.019 & 2.97 & $-1.3 e-7$ & -0.5 \\
M-4, M-5, M-6 & -0.208 & 0.002 & -0.04 & $-1.2 e-9$ & -0.006 \\
Z-7, Z-8, Z-9 & 0.32 & 0.0011 & -0.37 & $-2.7 e-8$ & $-1.9 e-20$ \\
J-7, J-8, J-9 & -0.16 & -0.0015 & 0.18 & $-1.711 e-7$ & -0.00034 \\
M-7, M-8, M-9 & -0.185 & 0.0019 & -0.02 & $3.6 e-9$ & 0.001 \\
& & & & 0.014 \\
\end{tabular}

member's frequency as the ternary function $\omega(N, A, T)$. MATLAB was used to fit the experimental data of natural frequency $\omega$, number of loading cycles $N$, loading amplitude $A$, and loading period $T$. Obviously the relationship of $\omega$ with $N, A$, and $T$ should be nonlinear. Thus, we use threevariable quadratic polynomial and three-variable cubic polynomial to fit the data of $\omega, N, A$, and $T$, as shown in the following equations:

$$
\begin{aligned}
\omega= & a_{0}+a_{1} N+a_{2} T+a_{3} A+a_{4} T A+a_{5} N A+a_{6} N T \\
& +a_{7} N^{2}+a_{8} T^{2}+a_{9} A^{2}, \\
\omega= & a_{0}+a_{1} N+a_{2} T+a_{3} A+a_{4} T A+a_{5} N A+a_{6} N T \\
& +a_{7} N^{2}+a_{8} T^{2}+a_{9} A^{2}+a_{10} A N T+a_{11} T^{2} A+a_{12} N A^{2} \\
& +a_{13} T A^{2}+a_{14} N^{2} T+a_{15} N^{2} A+a_{16} T^{2} N+a_{17} N^{3} \\
& +a_{18} T^{3}+a_{19} A^{3} .
\end{aligned}
$$

Take the nonlinear items in the above nonlinear models as new elements, as shown in Table 8. Then we can get linear models, as shown in Equations (14) and (15). Thus, the experimental data fitting problem changes from multivariate nonlinear fitting to multivariate linear fitting.

$$
\begin{aligned}
\omega= & a_{0}+a_{1} X_{1}+a_{2} X_{2}+a_{3} X_{3}+a_{4} X_{4}+a_{5} X_{5}+a_{6} X_{6} \\
& +a_{7} X_{7}+a_{8} X_{8}+a_{9} X_{9},
\end{aligned}
$$

$$
\begin{aligned}
\omega= & a_{0}+a_{1} X_{1}+a_{2} X_{2}+a_{3} X_{3}+a_{4} X_{4}+a_{5} X_{5}+a_{6} X_{6} \\
& +a_{7} X_{7}+a_{8} X_{8}+a_{9} X_{9}+a_{10} X_{10}+a_{11} X_{11}+a_{12} X_{12} \\
& +a_{13} X_{13}+a_{14} X_{14}+a_{15} X_{15}+a_{16} X_{16}+a_{17} X_{17} \\
& +a_{18} X_{18}+a_{19} X_{19} .
\end{aligned}
$$

Equations (14) and (15) have 9 and 19 independent valuables, respectively. But some independent valuables might have little impact on the dependent variable $\omega$. Stepwise regression method $[36,37]$ is used for multivariate linear fitting. In this method, through the screening of independent variables the saliency of the regression equation can be improved gradually until the "best" regression equation is found. The analysis steps of this method are as follows:

(1) Present all the independent valuables which may have influence on the dependent valuable according to relevant theories and experiences.

(2) Calculate the correlation coefficients of the independent variables to the dependent variable. Sort the independent variables according to their correlation coefficients absolute value from large to small.

(3) Set up one element linear fitting model using the independent variable with the largest correlation coefficient absolute value. Then test the significance of this fitting equation. If the test shows that the 

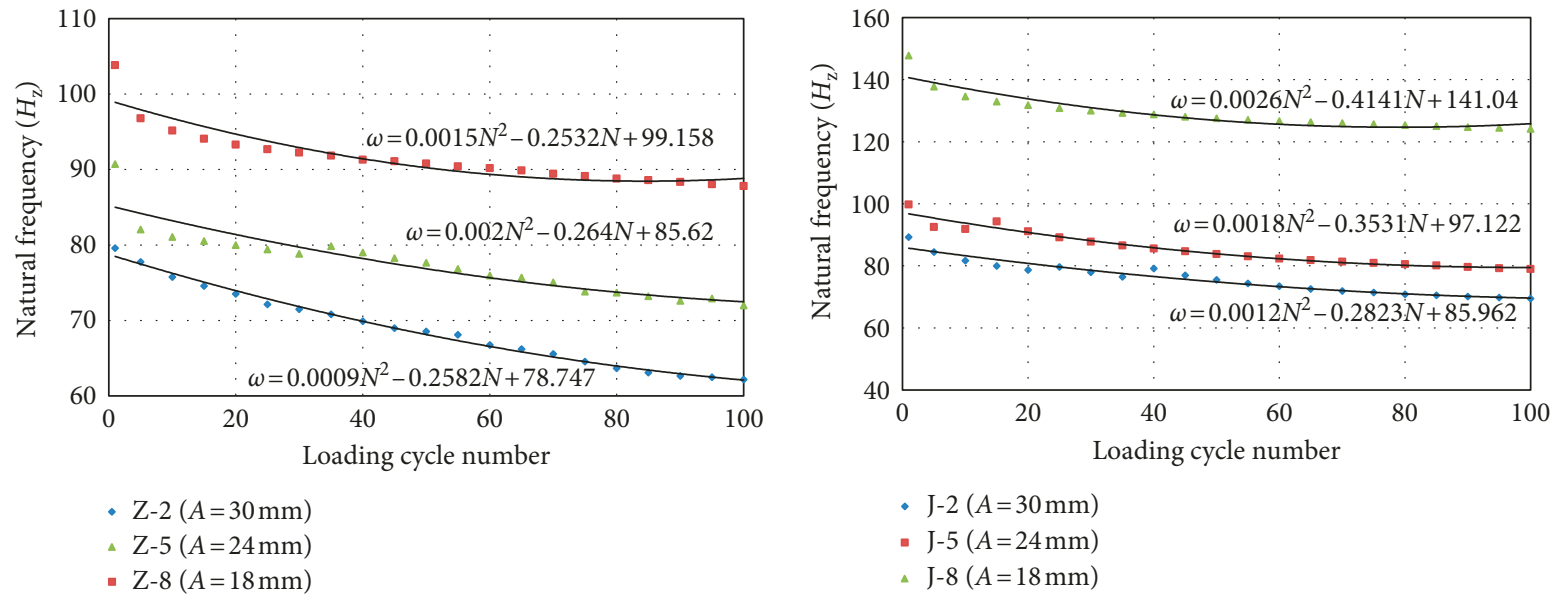

(a)
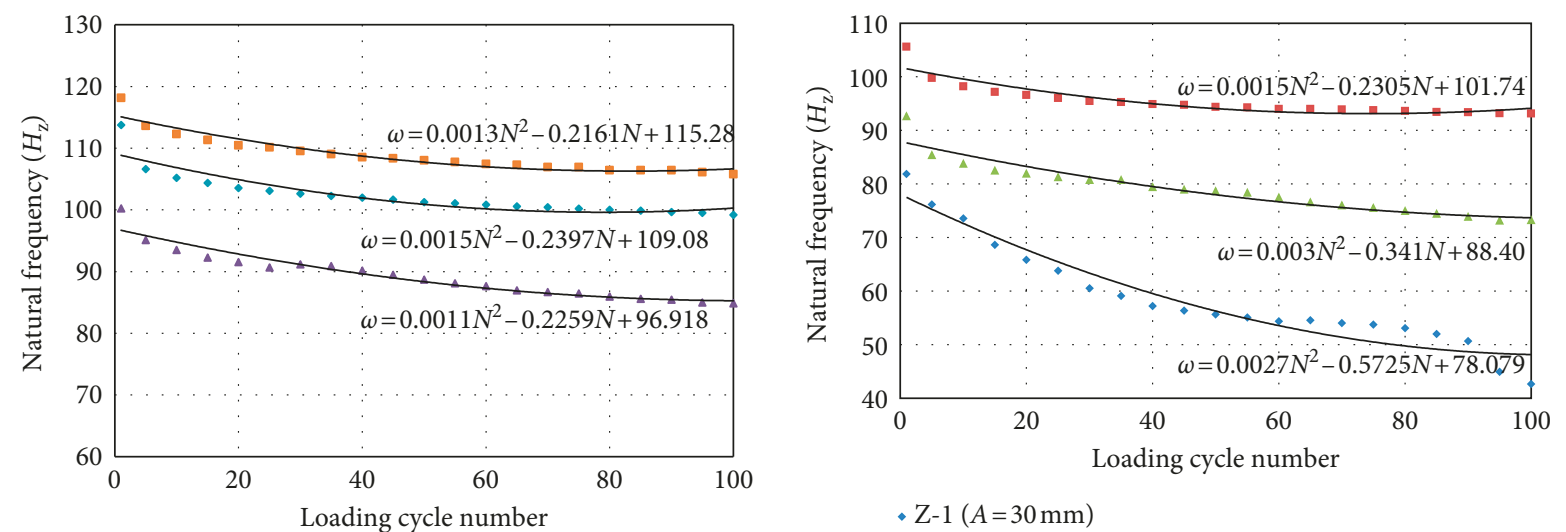

$\triangle \mathrm{M}-2(A=30 \mathrm{~mm})$

- M-5 $(A=24 \mathrm{~mm})$

- M-8 $(A=18 \mathrm{~mm})$

(c)

- Z-1 $(A=30 \mathrm{~mm})$
औ-4 $(A=24 \mathrm{~mm})$
- Z-7 $(A=18 \mathrm{~mm})$

(d)

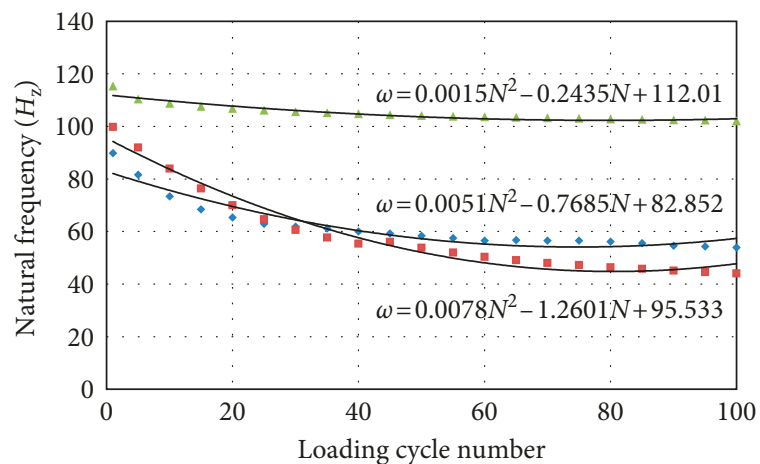

- J-1 $(A=30 \mathrm{~mm})$

- J-4 $(A=24 \mathrm{~mm})$

$\triangle \mathrm{J}-7(A=18 \mathrm{~mm})$

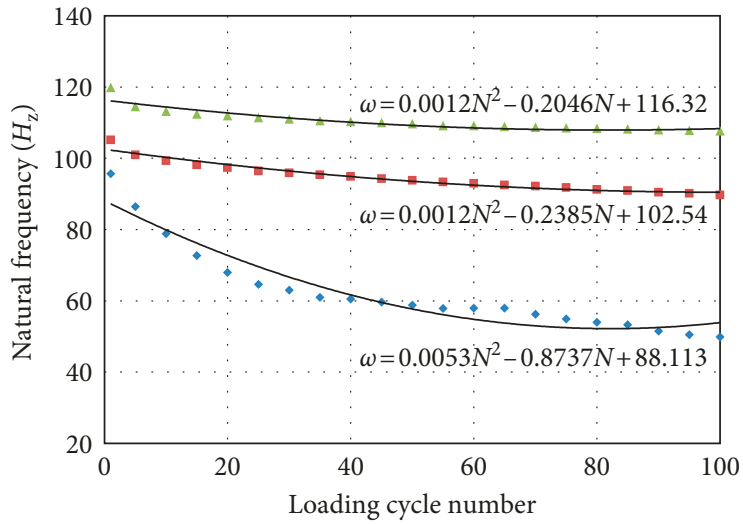

- $\mathrm{M}-1(A=30 \mathrm{~mm})$

M-4 $(A=24 \mathrm{~mm})$

M-7 $(A=18 \mathrm{~mm})$

(e)

Figure 11: Continued. 


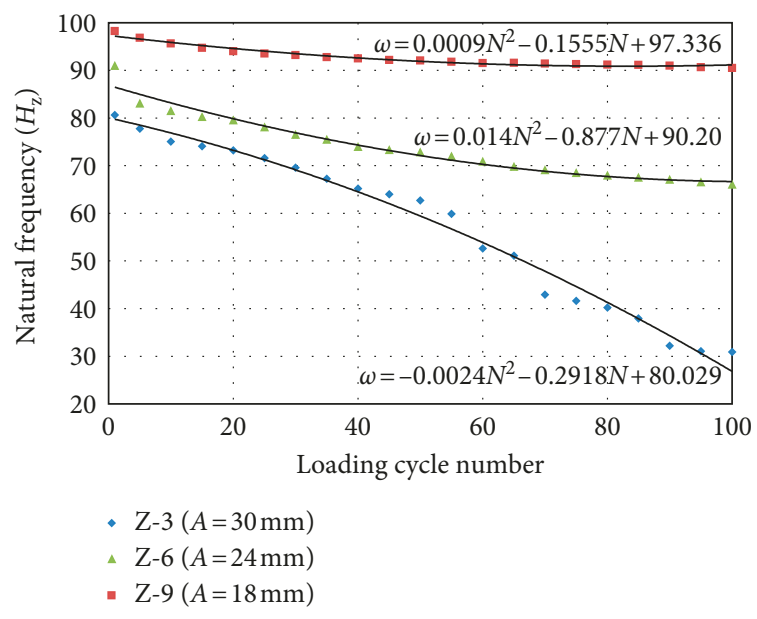

(g)

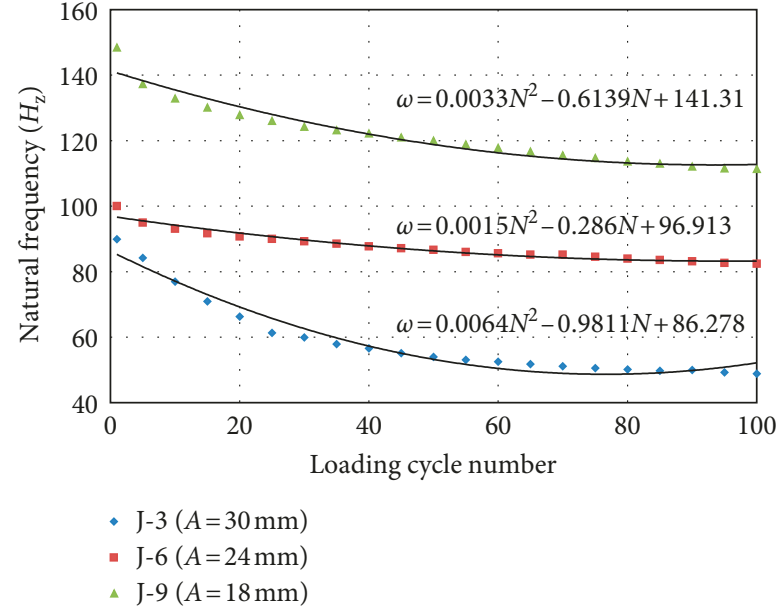

(h)

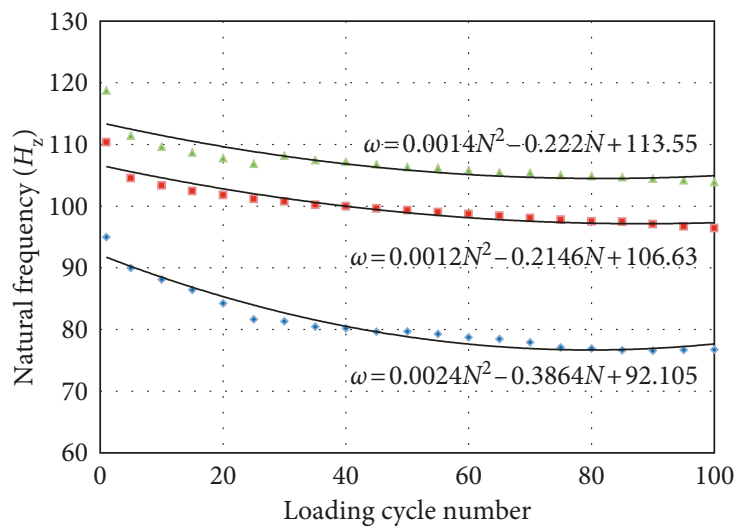

- M-3 $(A=30 \mathrm{~mm})$

- M-6 $(A=24 \mathrm{~mm})$

^ $\mathrm{M}-9(A=18 \mathrm{~mm})$

(i)

Figure 11: Natural frequency-change curves. (a) Z-2, Z-5, Z-8. (b) J-2, J-5, J-8. (c) M-2, M-5, M-8. (d) Z-1, Z-4, Z-7. (e) J-1, J-4, J-7. (f) M-1, M-4, M-7. (g) Z-3, Z-6, Z-9. (h) J-3, J-6, J-9. (i) M-3, M-6, M-9.

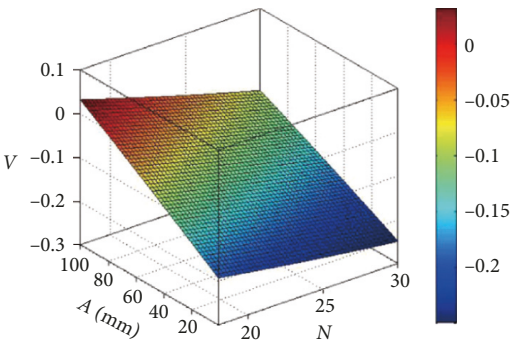

(a)

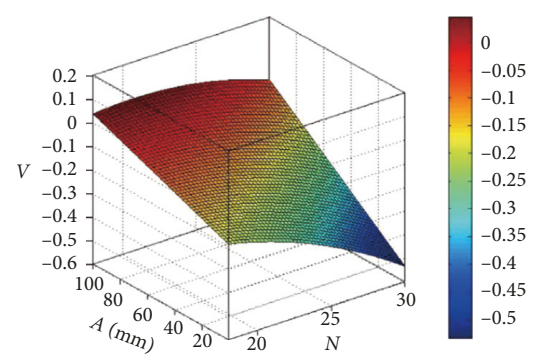

(d)

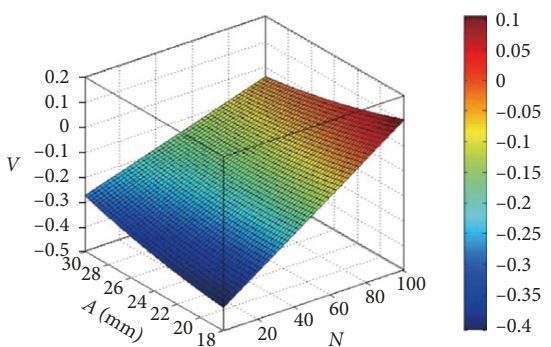

(b)

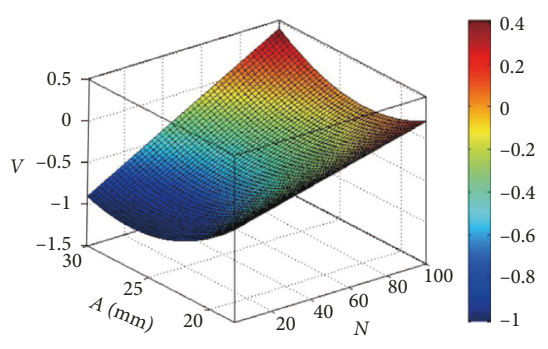

(e)

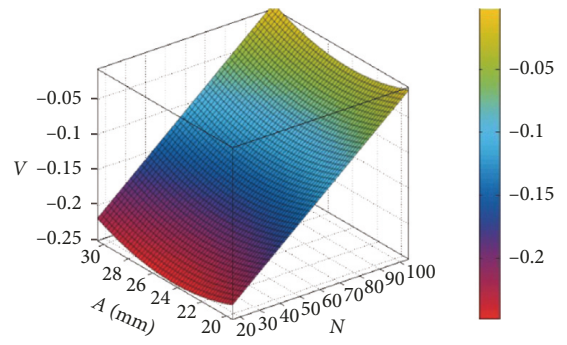

(c)

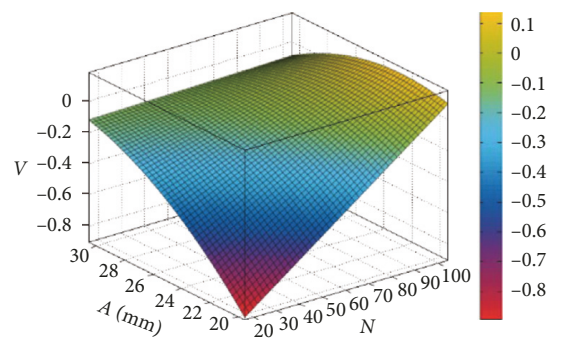

(f)

Figure 12: Continued. 


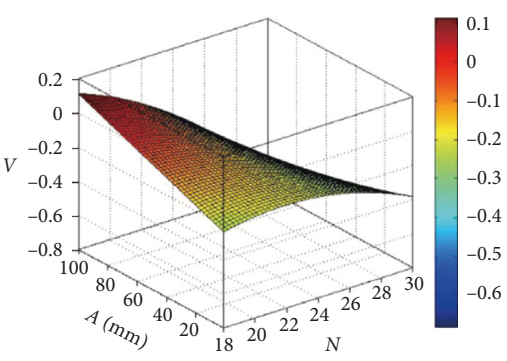

(g)

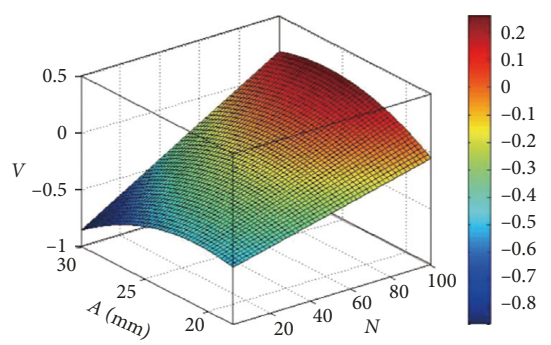

(h)

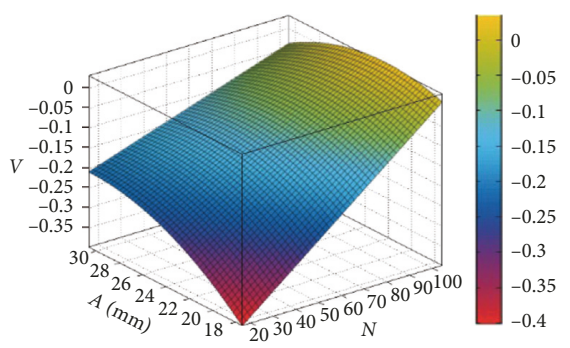

(i)

Figure 12: Damage-rate fitted surfaces of $V(A, N)$. (a) Z-2, Z-5, Z-8. (b) J-2, J-5, J-8. (c) M-2, M-5, M-8. (d) Z-1, Z-4, Z-7. (e) J-1, J-4, J-7. (f) M-1, M-4, M-7. (g) Z-3, Z-6, Z-9. (h) J-3, J-6, J-9. (i) M-3, M-6, M-9.

TABle 7: Coefficients of function $V(A, N)$.

\begin{tabular}{lccccc}
\hline \multirow{2}{*}{ Test members } & \multicolumn{4}{c}{ Coefficients of the function } \\
& $P_{00} P_{00}$ & $P_{10}$ & $P_{01}$ & $P_{20}$ & $P_{11}$ \\
\hline Z-2, Z-5, Z-8 & -0.075 & -0.0077 & 0.0033 & $6.3 e-5$ & $-5.2 e-5$ \\
J-2, J-5, J-8 & -0.37 & 0.009 & -0.01 & $9.539 e-8$ & -0.0002 \\
M-2, M-5, M-8 & 0.044 & 0.0019 & -0.03 & $-1.2 e-9$ & $1.77 e-19$ \\
\hline Z-1, Z-4, Z-7 & -0.36 & 0.032 & -0.0012 & -0.0012 & 0.00002 \\
J-1, J-4, J-7 & 4.9 & -0.0048 & -0.44 & $-4.8 e-8$ & 0.0005 \\
M-1, M-4, M-7 & -3.257 & 0.0206 & 0.185 & $-3.57 e-19$ & -0.0006 \\
\hline Z-3, Z-6, Z-9 & -1.56 & 0.12 & 0.013 & -0.0028 & -0.0007 \\
J-3, J-6, J-9 & -2.578 & -0.0049 & 0.2 & $5.356 e-8$ & 0.008 \\
M-3, M-6, M-9 & -1.207 & 0.0066 & 0.066 & $-2.4 e-9$ & -0.0005 \\
\hline
\end{tabular}

fitting effect is significant, then go to (4). And if it is not significant, stop modeling.

(4) Carry out the addition and elimination of the independent variables and the updating of fitting equations. The specific process is as below. According to the order of the absolute value of the correlation coefficient from large to small, the corresponding independent variables are introduced into the regression equation one by one. Each new variable is introduced, and every independent variable in the new regression equation should be tested for significance. And, also the significance of the new regression equation should be tested. If the test shows that the regression effect is not significant, the independent variable with less influence on the dependent variable is excluded and the regression equation is updated. After that, every independent variable in the updated regression equation will still need to be tested and eliminated, and then regression equation is updated again, and this is repeated this until each independent variable in the regression equation is significant. And then, the independent variable is reintroduced that has not been introduced before.

(5) And so on, until the introduced independent variables cannot be eliminated and new independent variables cannot be introduced.

The above analysis steps were run through MATLAB and the following results were gained. The fitting coefficients in
Equation (12) are given in Table 9. Also the judgment coefficients R2 which reflect the fitting degree are provided in Table 9 through MATLAB. The value of the judgment coefficient is from 0 to 1 . And the closer this coefficient is to 1 , the better the fitting degree is.

And the fitting coefficients in Equation (13) are given in Table 10. Comparing the judgment coefficients of quadratic polynomial model Equation (12) with that of cubic polynomial model Equation (13), it can be seen that the judgment coefficients of cubic polynomial model are larger than that of quadratic polynomial model and very close to 1 , which indicates that cubic polynomial model is better.

$$
\begin{aligned}
\omega(N, A, T)= & a_{0}+a_{1} N+a_{2} T+a_{3} A+a_{4} T A+a_{6} N T \\
& +a_{7} N^{2}+a_{10} A N T+a_{11} T^{2} A+a_{12} N A^{2} \\
& +a_{13} T A^{2}+a_{14} N^{2} T+a_{15} N^{2} A+a_{16} T^{2} N \\
& +a_{17} N^{3}+a_{18} T^{3}+a_{19} A^{3} .
\end{aligned}
$$

We can see that the coefficients $a_{5}, a_{8}$, and $a_{9}$ are zero. So, we can exclude the three corresponding items and obtain Equation (16). This is just the function model $\omega(N, A, T)$ indicating the relationship of $\omega$ with $N, A$, and $T$. It can be seen from the equation that if a test member's loading period and amplitude are known, the natural frequency-change process $\omega(N)$ can be determined. The frequency-change process represents an RC member's damage process. 
TABLE 8: Variable substitution.

\begin{tabular}{lccc}
\hline Equation (12) & & & Equation (13) \\
Original item & New item & Original item & New item \\
\hline$N$ & $X_{1}$ & $N$ & $X_{1}$ \\
$T$ & $X_{2}$ & $T$ & $X_{2}$ \\
$A$ & $X_{3}$ & $A$ & $X_{3}$ \\
$T A$ & $X_{4}$ & $T A$ & $X_{4}$ \\
$N A$ & $X_{5}$ & $N A$ & $X_{5}$ \\
$N T$ & $X_{6}$ & $N T$ & $X_{6}$ \\
$N^{2}$ & $X_{7}$ & $N^{2}$ & $X_{7}$ \\
$T^{2}$ & $X_{8}$ & $T^{2}$ & $X_{8}$ \\
$A^{2}$ & $X_{9}$ & $A^{2}$ & $X_{9}$ \\
& & $A N T$ & $X_{10}$ \\
& & $T^{2} A$ & $X_{11}$ \\
& & $N A^{2}$ & $X_{12}$ \\
& & $T A^{2}$ & $X_{13}$ \\
& & $N^{2} T$ & $X_{14}$ \\
& & $N^{2} A$ & $X_{15}$ \\
& & $T^{2} N$ & $X_{16}$ \\
& & $N^{3}$ & $X_{17}$ \\
& & $T^{3}$ & $X_{19}$ \\
\hline
\end{tabular}

TABle 9: Coefficients of quadratic polynomial model Equation (12).

\begin{tabular}{lccc}
\hline Coefficients & & Specimen & \\
& Z-1 Z-9 & J-1 J-9 & M-1 M-9 \\
\hline$a_{0}$ & 111.072 & 104.704 & 7.25751 \\
$a_{1}$ & 0.374128375718846 & 0.123087222141136 & -0.182407588719503 \\
$a_{2}$ & 12.3712456256323 & 118.886313511019 & 86.0463796394658 \\
$a_{3}$ & -1.61142709539306 & -10.8999491603412 & 1.81975050928462 \\
$a_{4}$ & 0 & 0.540879978562249 & 1.58776166995393 \\
$a_{5}$ & -0.0205457982698535 & -0.0113599390393166 & -0.0093710737740441 \\
$a_{6}$ & -0.0246603388200758 & -0.0468368467841787 & 0.0596143780058488 \\
$a_{7}$ & $6.63734555251616 e-05$ & 0.00055949107587472 & 0.00146298647471792 \\
$a_{8}$ & -2.72656082597941 & -25.9877593894723 & -24.8240056022407 \\
$a_{9}$ & 0 & 0.142689463548048 & -0.162714814814822 \\
Judgment coefficient $\left(R^{2}\right)$ & 0.888816 & 0.718614 & 0.924151 \\
Root mean square error & 4.65158 & 10.5467 & 4.27426 \\
\hline
\end{tabular}

\section{Conclusions}

Structural natural frequency-change characteristics under low cycle loading are important to identify structural damage caused by earthquakes. Harmonic vibration was used to simulate earthquake conditions. The impact of the loading period and loading amplitude on the structural natural frequency change during damage was analyzed. It was deduced that at any moment of loading, the instantaneous load, instantaneous displacement, and instantaneous frequency of a structure followed Equation (9), through which the structural natural frequency at any moment during damage can be calculated. Our analysis led to the following principal conclusions:

(1) The higher an RC member's stiffness, the greater the change of its natural frequency. Loading displacement has an obvious impact on the hysteretic curve, whereas the impact of the loading period is weak.
(2) The impact of the loading period on the structural damage process is mainly reflected in the damage speed. The function $V(N, T)$ obtained in this article indicates the relationship of the number of loading cycles $N$, loading period $T$, and damage rate $V$, as shown in Equation (10). It can be seen from the formula that the impact of the loading period on the damage rate is quadratic, and the relationship between $N$ and $V$ is mostly linear.

(3) The impact of the loading amplitude on the structural damage process is also mainly reflected in the damage speed. The function $V(A, N)$ indicates the relationship of the loading amplitude $A$ and number of loading cycles $N$ with the damage rate $V$, as shown in Equation (11). The impacts of the loading amplitude and number of loading cycles on the damage rate are both mostly linear.

(4) The function $\omega(N, A, T)$, indicating the relationship of $N, A, T$, and $\omega$, is shown in Equation (16). It 
TABLE 10: Coefficients of cubic polynomial model Equation (13).

\begin{tabular}{|c|c|c|c|}
\hline \multirow{2}{*}{ Coefficients } & \multicolumn{3}{|c|}{ Specimen } \\
\hline & Z-1 Z-9 & $\mathrm{J}-1 \sim \mathrm{J}-9$ & M-1 M-9 \\
\hline$a_{0}$ & 464.342 & 1709.89 & 497.628 \\
\hline$a_{1}$ & -0.273120219091463 & -0.801798388025358 & -1.00165849326798 \\
\hline$a_{2}$ & -210.811670727894 & -925.096418576694 & -237.681795491431 \\
\hline$a_{3}$ & -23.6752063223750 & -110.527720686002 & -26.2093732898868 \\
\hline$a_{4}$ & 18.1227919288250 & 85.2333666882871 & 21.9612377145612 \\
\hline$a_{5}$ & 0 & 0 & 0 \\
\hline$a_{6}$ & 0.323953069722666 & 0.395546851710759 & 0.557882540071001 \\
\hline$a_{7}$ & 0.00059579407036310 & 0.00258127311544728 & 0.00560634872500473 \\
\hline$a_{8}$ & 0 & 0 & 0 \\
\hline$a_{9}$ & 0 & 0 & 0 \\
\hline$a_{10}$ & -0.0138495848812992 & 0.00032744647692856 & 0.0131160269775290 \\
\hline$a_{11}$ & -4.44132996866784 & -5.86075713099332 & -4.85689087155177 \\
\hline$a_{12}$ & 0.00026004731450507 & -0.0003227936704906 & -0.0011537934068080 \\
\hline$a_{13}$ & 0.0923976583244754 & -1.18632392696069 & 0.0562704448782981 \\
\hline$a_{14}$ & $-7.822800905166 e-05$ & -0.0002285901078045 & -0.0008395572236522 \\
\hline$a_{15}$ & $5.1757805967185 e-06$ & $3.7955614628876 e-05$ & 0.00014072890415772 \\
\hline$a_{16}$ & -0.0137328563625555 & -0.0760408388477975 & -0.149006278920346 \\
\hline$a_{17}$ & $-1.320325398082 e-06$ & $-6.139924628880 e-06$ & $-3.620413282287 e-05$ \\
\hline$a_{18}$ & 13.3407306630236 & 15.3022606022822 & 13.6034019915526 \\
\hline$a_{19}$ & -0.0031497457424234 & 0.0424940950506309 & -0.0033490129536076 \\
\hline Judgment coefficient $\left(R^{2}\right)$ & 0.950952 & 0.962327 & 0.986819 \\
\hline Root mean square error & 3.09919 & 3.86832 & 1.788886 \\
\hline
\end{tabular}

includes the natural frequency-change process of an RC member under any arbitrary harmonic vibration. Once the period and the amplitude of a harmonic vibration are selected, the natural frequency-change process can be determined by Equation (16), which provides the basis for the identification and quantitative assessment of the structural damage process. It is also shown that when considering the loading period and loading amplitude at the same time, the impacts of $A$ and $T$ on the natural frequency $\omega$ are both complex nonlinear.

In future work, frequency-change experiments on RC members will be carried out under more loading periods and loading amplitudes to further verify our conclusions. More groups of RC members will be tested with different strengths, stiffnesses, and sizes to investigate the applicability of the above conclusions. The coefficients in Equation (16) are associated with structural attributes, so the quantitative relationship requires further study.

\section{Data Availability}

This paper contains a large number of data which were obtained from the horizontal cyclic loading test carried out in this study. The original experimental data mainly include the test members' displacements and the forces on the test members in the whole process from structural undamaged state to structural destruction state. The hysteretic curves in Figure 8 were just made from the data of test members' displacements and forces on the test members. So, Figure 8 can show these data. And the test members' natural frequencies come directly from the data of test members' displacements and forces on the test members using
Equation (9). The data of the test members' natural frequencies can be seen in Figures 9 or 11. Please note that Figure 8 provides 9 test members' hysteretic curves, but there were 27 test members in all. The reason is that hysteretic curve is not the problem this paper focuses on, and 27 figures would occupy more space. So, only 9 typical hysteretic curves are provided. What this paper focuses on is the test members' natural frequencies. All the data of the 27 test members' natural frequencies are given in Figures 9 or 11.

\section{Conflicts of Interest}

The authors declare that they have no conflicts of interest.

\section{Acknowledgments}

This work was financially supported by the Key Project of Chinese National Programs for Fundamental Research and Development (973 Program, Grant No. 2015CB057706), the National Natural Science Foundation of China (Grant No. 51108044), the Natural Science Foundation of Hunan Province (Grant No. 2018JJ2443), and the Research Project of the Educational Commission of Hunan Province of China (Grant No. 15C0053).

\section{References}

[1] A. Alvandi and C. Cremona, "Assessment of vibration-based damage identification techniques," Journal of Sound and Vibration, vol. 292, no. 1-2, pp. 179-202, 2006.

[2] M. Biswas, A. K. Pandey, and M. M. Samman, "Diagnostic experimental spectral modal analysis of a highway bridge," International Journal of Analytical and Experimental Modal Analysis, vol. 5, no. 1, pp. 33-42, 1990. 
[3] H. Y. Hwanga and C. Kimb, "Damage detection in structures using a few frequency response measurements," Journal of Sound and Vibration, vol. 270, no. 1-2, pp. 1-14, 2004.

[4] J. T. Kim, Y. S. Ryu, and C. B. Yun, "Vibration-based method to detect prestress-loss in beam-type bridges," in Proceedings of SPIE 5057, Smart Structures and Materials 2003: Smart Systems and Nondestructive Evaluation for Civil Infrastructures, vol. 5057, San Diego, California, USA, August 2003.

[5] A. Messina, T. Contursi, and E. Williams, "A multiple damage evaluation using natural frequency changes," in Proceedings of 15th International Modal Analysis Conference, vol. 2, pp. 658-664, Orlando, FL, USA, February 1997.

[6] O. Salawu, "Detection of structural damage through changes in frequency: a review," Engineering Structures, vol. 19, no. 9, pp. 718-723, 1997.

[7] R. P. C. Sampaio, N. M. M. Maia, and J. M. M. Silva, "Damage detection using the frequency-response-function curvature method," Journal of Sound and Vibration, vol. 226, no. 5, pp. 1029-1042, 1999.

[8] J. F. Unger, A. Teughels, and G. D. Roeck, "Damage detection of a prestressed concrete beam using modal strains," Journal of Structural Engineering, vol. 131, no. 9, pp. 1456-1463, 2005.

[9] M. A. Abraham, S. Park, and N. Stubbs, "Loss of prestress prediction based on damage nondestructive location algorithms," in Proceedings of SPIE 2446 Smart Structures and Materials 1995: Smart Systems for Bridges, Structures, and Highways, vol. 2446, San Diego, CA, USA, April 1995.

[10] G. Fraraccio, A. Brügger, and R. Betti, "Experimental studies on damage detection in frame structures using vibration measurements," Shock and Vibration, vol. 17, no. 6, pp. 697-721, 2010.

[11] S. Huang, X. Guo, D. Sun, and Q. Meng, "Shaking table seismic test on performance of frame-structure with lightweight infilled walls," Engineering Machanics, vol. 31, no. 9, pp. 182-189, 2014, in Chinese.

[12] I. Laory, T. N. Trinh, I. F. C. Smith, and J. M. W. Brownjohn, "Methodologies for predicting natural frequency variation of a suspension bridge," Engineering Structures, vol. 80, pp. 211-221, 2014.

[13] M. Massenzio, E. Jacquelin, and P. A. Ovigne, "Natural frequency evaluation of a cracked RC beam with or without composite strengthening for a damage assessment," Materials and Structures, vol. 38, no. 284, pp. 865-873, 2005.

[14] I. Maruyama, "Multi-scale review for possible mechanisms of natural frequency change of reinforced concrete structures under an ordinary drying condition," Journal of Advanced Concrete Technology, vol. 14, no. 11, pp. 691-705, 2016.

[15] V. Mohan, S. Parivallal, K. Kesavan, B. Arunsundaram, A. K. F. Ahmed, and K. Ravisankar, "Studies on damage detection using frequency change correlation approach for health assessment," Procedia Engineering, vol. 86, pp. 503-510, 2014.

[16] Y. Lee and M. Chung, "A study on crack detection using eigenfrequency test data," Computers \& Structures, vol. 77, no. 3, pp. 327-342, 2000.

[17] G. M. Owolabi, A. S. J. Swamidas, and R. Seshadri, "Crack detection in beams using changes in frequencies and amplitudes of frequency response functions," Journal of Sound and Vibration, vol. 265, no. 1, pp. 1-22, 2003.

[18] O. Yang, Y. Liu, H. Li, and J. P. Ou, "Cable bridge modal parameter statistical analysis under the time varying environment coupled with damage," Chinese Journal of Computational Mechanics, vol. 27, no. 3, pp. 457-463, 2010, in Chinese.
[19] C. W. Kim and M. Kawatani, "Pseudo-static approach for damage identification of bridges based on coupling vibration with a moving vehicle," Structure and Infrastructure Engineering, vol. 4, no. 5, pp. 371-379, 2008.

[20] X. Li, J. Wang, and M. Luo, "Pseudo-static experiment and analysis on seismic behavior of the RC columns strengthened by GHPFRCC," Polish Maritime Research, vol. 22, no. 1, pp. 56-60, 2015.

[21] Ministry of Housing and Urban-Rural, Development of the People's Republic of China (MOHURD), Code for Design of Concrete Structures (GB50010-2010), English version, MOHURD, Beijing, China, 2015.

[22] J. S. Shortreed, F. Seible, and G. Benzoni, "Simulation issues with a real-time, full-scale seismic testing system," Journal of Earthquake Engineering, vol. 6, no. 1, pp. 185-201, 2002.

[23] R. T. Leon and G. G. Deierlein, "Considerations for the use of quasi-static testing," Earthquake Spectra, vol. 12, no. 1, pp. 87-109, 1996.

[24] D. J. Ewins, Modal Testing: Theory and Practice, John Wiley \& Sons, New York, NY, USA, 2nd edition, 2000.

[25] E. Kausal, "New seismic testing method I: fundamental concept," Journal of Engineering Mechanics, vol. 124, no. 5, pp. 565-570, 1998.

[26] N. Stubbs and R. Osegueda, "Global non-destructive damage evaluation in solid," International Journal of Analytical and Experimental Modal Analysis, vol. 5, no. 2, pp. 67-79, 1990.

[27] X. Zhang, Nonlinear Analysis of Reinforced Concrete Seismic Member, Science Press, Beijing, China, 2003, in Chinese.

[28] S. Rajasekaran, Structural Dynamics of Earthquake Engineering: Theory and Application using Mathematica and MATLAB, CRC Press LLC, Boca Raton, FL, USA, 2009.

[29] H. Cohen, Complex Analysis with Applications in Science and Engineering, Springer, New York, NY, USA, 2nd edition, 2007.

[30] J. Li, Y. Peng, and Q. Yan, "Modeling and simulation of fluctuating wind speeds using evolutionary phasespectrum," Probabilistic Engineering Mechanics, vol. 32, pp. 48-55, 2013.

[31] E. J. Setzler and H. Sezen, "Model for the lateral behavior of reinforced concrete columns including shear deformations," Earthquake Spectra, vol. 24, no. 2, pp. 493-511, 2008.

[32] H. Yoshikawa and T. Miyagi, "Ductility and failure modes of single reinforced concrete columns," Nippon Konkurito Kogaku Kyokai Ronbunshu, vol. 51, pp. 229-244, 1999.

[33] A. E. Charalampakis and V. K. Koumousis, "On the response and dissipated energy of Bouc-Wen hysteretic model," Journal of Sound and Vibration, vol. 309, no. 3-5, pp. 887895, 2008.

[34] M. Sága, M. Vaško, P. Kopas, and L. Jakubovičová, “Application of Karray-Bouc hysteretic model for cumulative damage calculation using energy fatigue curve," Applied Mechanics and Materials, vol. 611, pp. 32-39, 2014.

[35] R. W. Clough and J. Penzien, Dynamics of Structures, Computers \& Structures, Inc., Berkeley, CA, USA, 3rd edition, 2003.

[36] E. Grechanovsky, "Stepwise regression procedures: overview, problems, results, and suggestions," Annals of the New York Academy of Sciences, vol. 491, no. 1, pp. 197-232, 1987.

[37] N. Sun, S. Yang, and W. W. Yeh, "A proposed stepwise regression method for model structure identification," Water Resources Research, vol. 34, no. 10, pp. 2561-2572, 1998. 


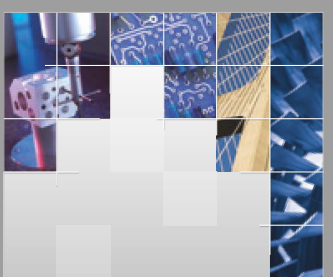

\section{Enfincering}
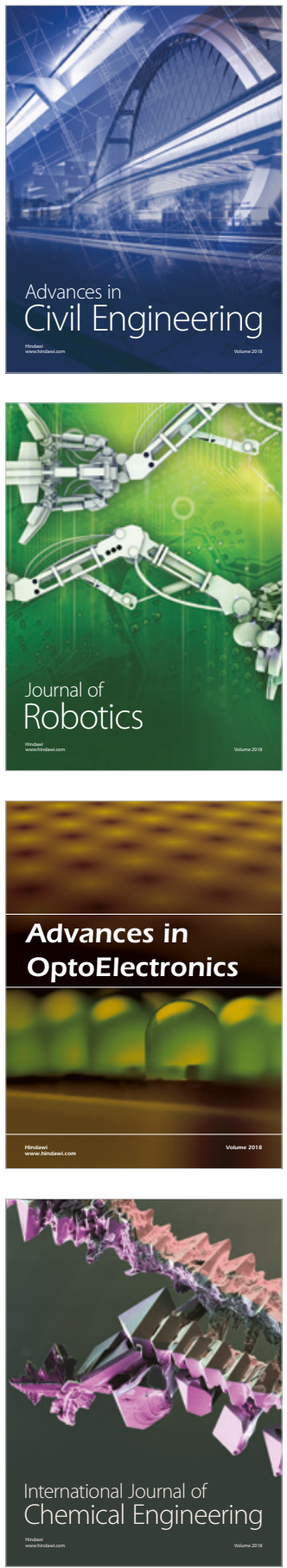

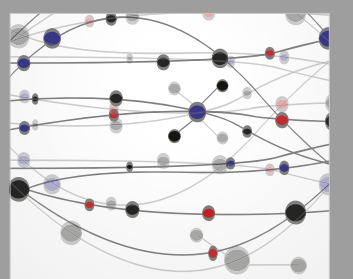

\section{Rotating \\ Machinery}

The Scientific World Journal

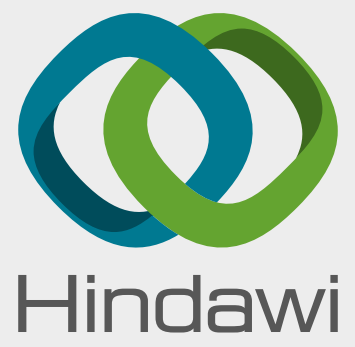

Submit your manuscripts at

www.hindawi.com
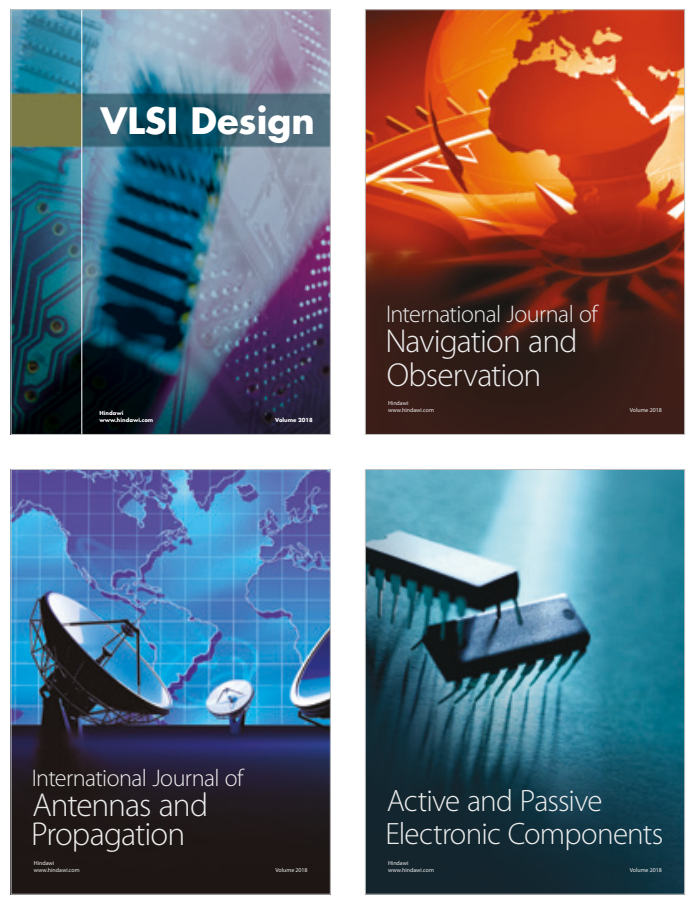
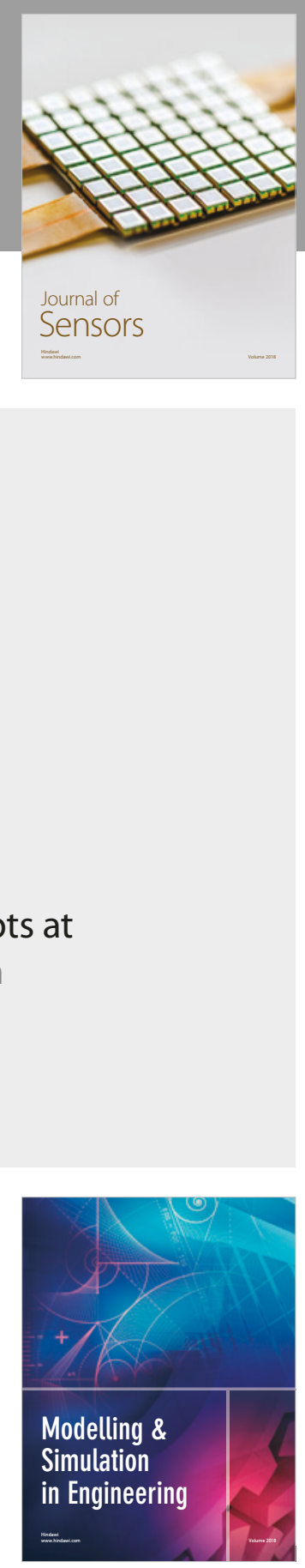

\section{Advances \\ Multimedia}
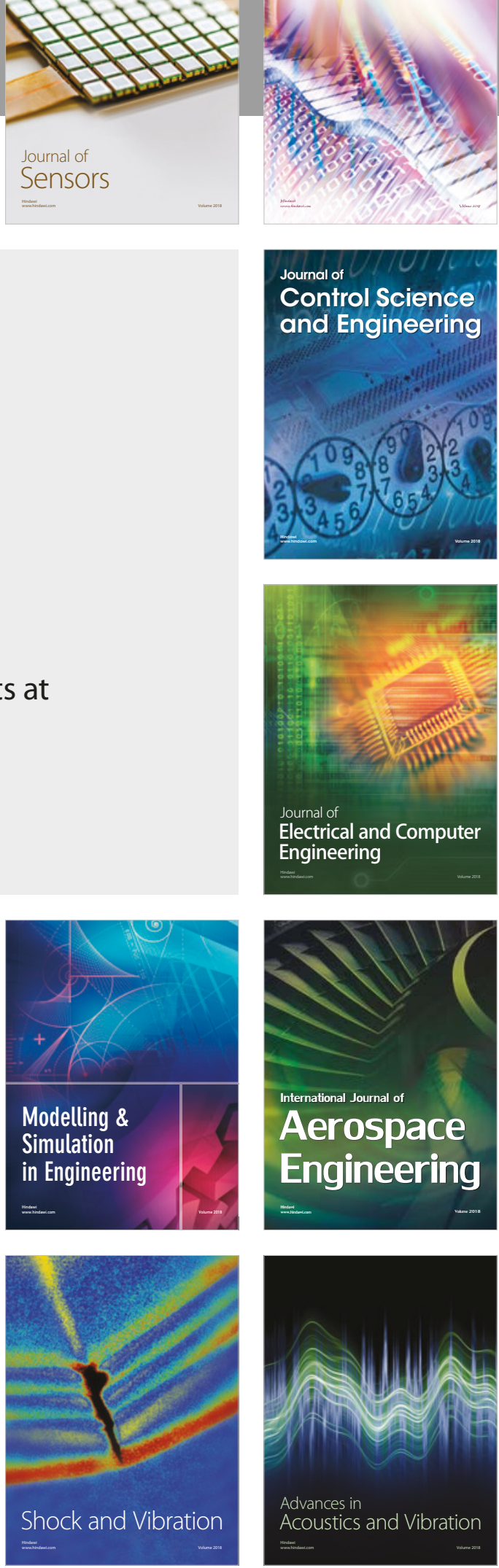